\title{
Unidades de ensino potencialmente significativas em indução eletromagnética: um estudo sobre a conceitualização de estudantes de nível superior ${ }^{+*}$
}

Glauco Cohen Pantoja ${ }^{1}$

Universidade Federal do Oeste do Pará

Santarém - PA

Marco Antonio Moreira ${ }^{1}$

Universidade Federal do Rio Grande do Sul

Porto Alegre - RS

\section{Resumo}

Discutimos os resultados da aplicação de duas Unidades de Ensino Potencialmente Significativas (UEPS) para abordar o conceito de indução eletromagnética em disciplinas de eletromagnetismo do ciclo básico do Ensino Superior, em dois contextos distintos. Estas unidades tiveram nove encontros de 100 minutos, divididos em sessões de aula expositivo-dialogada de 40 minutos de duração, nas quais o professor abordava o conteúdo de maneira sintética, e em sessões de resolução de problemas de 60 minutos de duração, nas quais eram propostos problemas para serem resolvidos em grupo. A teoria dos campos conceituais foi utilizada como referencial teórico e a metodologia de análise de conteúdo foi empregada para estudar os modos de conceitualização desenvolvidos pelos alunos na solução dos problemas propostos nas unidades. Restringimos a análise de dados a respostas de problemas oriundos de duas classes de situações, quais sejam, descrição de interações eletromagnéticas e representação simbólica do campo eletromagnético. Na avaliação diagnóstica, identificamos tentativas inicialmente frustradas dos estudantes de adaptar conhecimentos prévios obtidos dos contextos da eletrostática e da magnetostática para descrever campos eletrodinâmicos. No decorrer das UEPS, em ambos os

\footnotetext{
+ Potentially meaningful teaching units on electromagnetic induction: a study on higher education students' conceptualization

* Recebido: 9 de julho de 2020. Aceito: 2 de julho de 2021.

${ }^{1}$ E-mails: glauco.pantoja@ufopa.edu.br; moreira@if.ufrgs.br
} 
contextos, destacamos a existência de padrões de adaptação dos modos de conceitualização da maioria dos alunos para aqueles julgados cientificamente adequados. Os estudantes parecem começar um processo de desvinculação parcial da noção instrumentalista do campo eletromagnético e passam a adotar modelos mais realistas deste campo, além de aparentarem ganhar familiaridade com representações simbólicas mais relacionais e abstratas do campo eletromagnético.

Palavras-Chave: UEPS; Indução Eletromagnética; Campos Conceituais.

\begin{abstract}
We discuss the results of the implementation of two Potentially Meaningful Teaching Units for approaching the concept of electromagnetic induction in Higher Education basic cycle electromagnetism subjects in two contexts. These unities had nine classes of 100 minutes each, which were split in expositive-dialogic lecture sessions of 40 minutes, when the teacher addressed the content synthetically, and problem-solving sessions of 60 minutes, when students solved problems in groups. Conceptual field theory was used as theoretical framework and the methodology of content analysis was carried out to investigate conceptualization modes developed by students in problem-solving. We restricted data analysis to answers for problems derived from two classes of situations, namely, description of electromagnetic interactions and symbolic representation of the electromagnetic field. In diagnostic evaluation, we identified initial frustrated students' attempts of adapting prior knowledge obtained from electrostatics and magnetostatic contexts for describing electrodynamic fields. Along the UEPS, in both contexts, we highlighted the existence of adaptation patterns of conceptualization modes due to most part of the students to the ones deemed scientifically adequate. Learners seem to start a process of partial detachment of the instrumentalist notion of the electromagnetic field and begin to adopt more realist models of this field, besides that, they apparently become more familiar with relational and abstract symbolic representations of the electromagnetic field.
\end{abstract}

Keywords: PMTU; Electromagnetic Induction; Conceptual Fields. 


\section{Introdução}

O panorama descritivo da pesquisa em Ensino de Física aponta para poucos estudos sobre aprendizagem do conceito de indução eletromagnética. Embora os trabalhos desenvolvidos sobre concepções desse conceito sejam relativamente escassos, eles nos proveem uma quantidade de dados suficientes para concluir ser difícil aprendê-lo. Zuza, García e Guisasola (2012) apontam, em uma revisão de literatura sobre o tema, diversos erros de pensamento empregados por estudantes para resolver problemas envolvendo o conceito de indução eletromagnética. Algumas destas concepções são também destacadas por pesquisas mais recentes (GUISASOLA; ZUZA; ALMUDÍ, 2013; ZUZA et al., 2014; KUO; WIEMAN, 2016; JELICIC; PLANINIC; PLASINIC, 2017). As concepções são arroladas na sequência:

- confundir a área do circuito e a área varrida pelo movimento do circuito; atribuir ao campo magnético o papel de gerador da corrente elétrica induzida; confundir entre campos eletrostáticos e campos não eletrostáticos; igualar força eletromotriz (fem) à diferença de potencial; descrever incorretamente as relações entre os conceitos de campo eletromagnético e força eletromagnética; confundir fluxo magnético com o campo magnético; supor o fluxo como um conceito sem significado físico; associar o fluxo magnético a uma suposta fluidez do campo magnético; confundir a variação temporal do fluxo magnético com o próprio fluxo magnético; não reconhecer a variação temporal de fluxo magnético como fonte de força eletromotriz; confundir as forças elétrica e magnética; determinar a direção da força magnética de forma errônea; não diferenciar epistemológica e ontologicamente entre os programas coulombiano e maxwelliano; não relacionar conceitos centrais da teoria eletromagnética; não reconhecer fenômenos de indução eletromagnética; não conseguir relacionar fem induzida, corrente induzida e sentido da corrente; não reconhecer fenômenos de indução eletromagnética quando não há corrente elétrica induzida; supor o campo eletromagnético um suporte para transferência de força; atribuir a fem ao fluxo magnético; estabelecer relação de proporção direta entre a corrente elétrica que produz a fem e a corrente elétrica induzida.

Muitas dificuldades dos estudantes estão vinculadas a processos de ensino nãoproblematizadores, lineares, excessivamente narrativos e transmissivos. Neste contexto, as Unidades de Ensino Potencialmente Significativas (UEPS) se apresentam como alternativa ao modelo tradicional de ensino (MOREIRA, 2011), pois se estruturam sobre teorias fundadas em torno do conceito de aprendizagem significativa. Uma quantidade razoável de trabalhos tem demonstrado que a abordagem ao ensino por meio de UEPS fornece condições para ocorrência de aprendizagem significativa na etapa predicativa de conhecimento sobre eletromagnetismo (PANTOJA; MOREIRA, 2019; PANTOJA; MOREIRA, 2020). Não obstante, ainda há poucos estudos sustentando que esta metodologia facilite processos de aprendizagem na etapa operatória do conhecimento. 
As formas operatória e predicativa do conhecimento são estudadas simultaneamente através da conceitualização, na teoria dos campos conceituais (VERGNAUD, 2009). Tal construto pode ser entendido como a maneira pela qual os indivíduos se referem a objetos e situações do mundo com o uso de conceitos. Assim, propomos a seguinte questão para nortear o trabalho: "como estudantes de nível superior desenvolvem processos de conceitualização em uma unidade de ensino potencialmente significativa abordando o conceito de indução eletromagnética?". Para responder a esta pergunta, apresentamos os resultados da aplicação de duas UEPS sobre o conceito de indução eletromagnética em dois contextos diferentes. As análises de dados foram desenvolvidas tomando como referencial teórico a teoria dos campos conceituais e como referencial metodológico a análise de conteúdo (BARDIN, 2008).

\section{Referencial teórico}

A teoria dos campos conceituais é uma teoria desenvolvimentista que abarca processos cognitivos ocorrentes na escola e fora dela. Seu objetivo fundamental é o de encontrar conexões frutíferas entre a ação e a verbalização. Este referencial toma como fundamentais três premissas: a) processos cognitivos são adaptativos; b) o desenvolvimento cognitivo é função tanto da ação como da representação; c) o estudo da atividade deve ser feito em situação (VERGNAUD, 2009).

Gérard Vergnaud, o autor da teoria, indica a existência de uma relação dialética entre duas formas de conhecer, quais sejam, a operatória, subjacente às ações dos indivíduos, e predicativa, explícita e expressa em formas simbólicas e linguísticas (VERGNAUD, 2013). $\mathrm{Na}$ visão deste psicólogo, ambas as modalidades de conhecer são relevantes para o que ele chama de conceitualização, o ato de estabelecer referência ao real usando conceitos (VERGNAUD, 2009). É pouco comum encontrarmos trabalhos que levem em conta a forma operatória da cognição, pois a maioria enfatiza o estudo de processos linguísticos e representativos tornados explícitos pelos estudantes.

Vergnaud aborda o desenvolvimento cognitivo e a aprendizagem de maneira complexa usando como elemento central a conceitualização. Desta forma, ao se levar em conta tanto a ação como a representação, somos levados a considerar estes dois elementos simultaneamente, o que implica ação entremeada de linguagem, além de acarretar funcionamento da última ancorado na primeira. Desconsiderar isto é construir um avatar behaviorista do processo, do ponto de vista de Vergnaud (2013).

Outra consequência de considerar a conceitualização como pedra angular da aprendizagem e do desenvolvimento é a reorganização do conceito de conceito. Para Vergnaud (2009) a ação dificilmente é endereçada a objetos, pois costuma ser dirigida a situações e estas envolvem conjuntos de objetos inter-relacionados. Desta forma, a aprendizagem de conceitos deve levar em conta as situações que os tornam úteis e significativos. Classicamente, conceitos são entendidos como possuindo significados e representações, mas esta abordagem é apropriada para a investigação da etapa predicativa do 
conhecimento, uma vez que a linguagem estabelece referência direta entre significados e significantes independentemente das situações (VERGNAUD, 2013). O conceito na perspectiva dos campos conceituais é, então, composto de três conjuntos: o de situações que tornam o conceito útil e significativo (referente); o de invariantes operatórios que lhe dão significado (significado); e o de representações que o simbolizam (significante).

Neste contexto, situações são entendidas como tarefas (estruturadas ou não estruturadas) divisíveis em subtarefas. Invariantes operatórios são divididos em teoremas-emação e conceitos-em-ação. Os primeiros são proposições tomadas como verdadeiras sobre a realidade, enquanto os segundos são categorias consideradas pertinentes sobre o real. Como proposições são constituídas de categorias relacionadas e as categorias precisam de relações para ganharem sentido, então teoremas-em-ação e conceitos-em-ação não podem ser reduzidos uns aos outros. Já as representações linguísticas, simbólicas ou gestuais, representam situações e invariantes operatórios utilizados pelos sujeitos na análise e no domínio de situações.

Para dar conta tanto da ação quanto da simbolização, Vergnaud (2013) elenca o conceito de esquema para analisar a atividade, uma vez que este carrega consigo ambos os elementos mencionados. Respeitando a tese de que conhecimento é adaptação, o autor aponta que os esquemas se adaptam a situações. Enquanto a forma predicativa da cognição está mais vinculada à enunciação dos objetos por meio de linguagem, as ações referem-se mais a tarefas, e como estas podem ser expressas linguisticamente, é possível abordar ambas simultaneamente por meio do estudo da interação entre esquemas e situações (VERGNAUD, 2009).

É possível definir esquema de quatro formas diferentes, mas complementares, quais sejam: a) uma totalidade dinâmica funcional, isto é, uma entidade não-engessada, flexível, que serve à possibilidade de adaptação (VERGNAUD, 2013); b) a organização invariante da ação para uma classe dada de situações, ou seja, uma forma de organizar ação (e simbolização, consequentemente); c) uma entidade composta de objetivos e antecipações que permitem a previsão de possibilidades para a atividade, de regras de ação do tipo SE... ENTÃO que compõem a parte gerativa do esquema, de invariantes operatórios componentes da parte conceitual do esquema, e de possibilidades de inferência que tornam possível a continuação da atividade (VERGNAUD, 2009); d) uma função que toma seus valores de entrada em um espaço temporalizado a $n$ dimensões e que produz valores de saída a um espaço igualmente temporalizado a $n^{\prime}$ dimensões (com $n$ e $n^{\prime}$ muito grandes). A definiç̧ão d é importante, pois aproxima o esquema da noção de algoritmo (VERGNAUD, 2009; 2013). Entretanto, esquemas são mais gerais que algoritmos, já que não precisam levar a atividade a uma conclusão em um número finito de passos, como fazem os últimos.

Vergnaud concebe o conhecimento organizado em campos conceituais, conjuntos de situações e problemas que podem ser abordados usando-se conceitos, procedimentos e representações de diferentes tipos, mas correlacionados (VERGNAUD, 2009). Estes campos 
conceituais são dominados paulatinamente pelos indivíduos e podem ser considerados, literalmente, um campo de conceitos. Por assim ser, um conceito não adquire seu sentido a partir de somente uma situação e tampouco uma situação é resolvida somente com um conceito, o que implica em pensar relações. O estudo da evolução de um indivíduo em um campo conceitual exige, então, o estudo de como seus esquemas se adaptam às situações. No entanto, nem sempre o indivíduo possui esquemas desenvolvidos para tal. Como proceder neste caso?

Fanaro, Otero e Moreira (2009) apontam que a ação tem caráter duplo: contingente e sistemático. A ação é sistemática quando os indivíduos já dispõem de esquemas para serem adaptados às situações, ou seja, existem regularidades claras na conceitualização, o que não quer dizer que a ação seja sempre a mesma, mas que ela se organiza de forma invariante. Por outro lado, a ação é contingente quando os sujeitos não possuem esquemas e devem desenvolver a conceitualização improvisando na mobilização de conhecimentos prévios para alcançar uma solução. Quando a situação nunca foi antes resolvida, a conceitualização se torna um processo oportunista, pois o sujeito deverá lançar mão de todos os recursos cognitivos possíveis para conduzi-la. Quando o nível de contingência da ação atinge o grau mínimo de estruturação, a saber, o estágio oportunista, o indivíduo pode tentar combinar e recombinar esquemas, misturar invariantes operatórios de esquemas prévios, construir novos invariantes operatórios ou mesmo criar novos esquemas, et cetera, para alcançar a conceitualização, ou seja, o sujeito faz o que for preciso para identificar objetos e propriedades do real por meio de conceitos.

Com base no exposto por esses autores, propomos o conceito de modo de conceitualização ${ }^{2}$ para nos referirmos à maneira pela qual o indivíduo articula e mobiliza invariantes operatórios em situação, o que nos permite descrever e caracterizar o oportunismo e a contingência da conceitualização. Nesta perspectiva, um esquema pode ser entendido como um modo de conceitualização sistemático, organizado de maneira invariante para uma classe de situações. Visamos, neste artigo, identificar possíveis modos de conceitualização empregados pelos estudantes no domínio de situações envolvendo o conceito de indução eletromagnética. Trabalhos sobre o uso de modos de conceitualização em eletrostática (PANTOJA; MOREIRA, 2020) e magnetostática (PANTOJA; MOREIRA, 2019) já foram desenvolvidos anteriormente. Os resultados dessas pesquisas apontam que UEPS em eletrostática e magnetostática proveem condições para que os alunos construam novos modos de conceitualização, que se aproximam progressivamente de representações científicas, em um grau considerável.

\footnotetext{
${ }^{2}$ Usamos forma de conceitualização como sinônimo.
} 


\section{Metodologia}

Dividiu-se a metodologia em duas partes para discutir-se separadamente a construção das UEPS (metodologia didática) e a forma pela qual os dados resultantes da aplicação das UEPS foram coletados e analisados (metodologia investigativa).

As UEPS são compostas por um rol de estratégias de ensino visando prover condições de ocorrência para a aprendizagem significativa. Oito passos programáticos orientando o ensino progressivo do conteúdo, além de dez princípios relacionados ao conceito de aprendizagem significativa, estão subjacentes a estas (MOREIRA, 2011). Assim, visamos o aumento da complexidade e da relacionabilidade entre conceitos durante o processo de ensino.

Os aspectos sequenciais de uma UEPS são descritos a seguir $\left.{ }^{3}: 1\right)$ definir o tópico específico a ser abordado (seleção de conteúdo); 2) criar e propor situações-problema para levar os alunos a explicitarem seus conhecimentos prévios (emergência do conhecimento prévio); 3) propor situações-problema em nível introdutório para facilitar a introdução do conhecimento que se quer ensinar, levando em conta os conhecimentos prévios do aluno (problematização do conhecimento prévio); 4) apresentar o conteúdo a ser ensinado de acordo com o princípio da diferenciação progressiva (diferenciação progressiva); 5) retomar aspectos mais gerais do conteúdo a ser ensinado/aprendido em um maior nível de complexidade, dar novos exemplos e seguir a reconciliação integradora (reconciliação integrativa); 6) concluir a unidade dando seguimento ao processo de diferenciação progressiva retomando as características mais relevantes do conteúdo, buscando ao mesmo tempo a reconciliação integradora (diferenciação integrativa); 7) realizar a avaliação individual somativa. Nesta avaliação devem ser propostas situações-problema que impliquem compreensão e que evidenciem captação de significados (avaliação somativa); 8) análise do êxito da UEPS (MOREIRA, 2011).

A diferenciação progressiva é o princípio programático afirmando que conceitos mais gerais do conteúdo devem ser apresentados no início do processo de ensino e devem ser diferenciados de forma progressiva ao longo do processo em termos de especificidade. A reconciliação integrativa é o princípio programático apontando que o professor deve explorar relações entre conceitos através do destaque de semelhanças e de diferenças ou mesmo por meio da reconciliação de discrepâncias reais e aparentes (MOREIRA, 2011).

As UEPS para ensinar os conceitos de campo eletromagnético e de indução eletromagnética foram desenvolvidas em nove aulas (de dois períodos cada). Antes destas, foram abordadas três outras UEPS sobre campos escalares e vetoriais, campos elétricos e campos magnéticos. As nove aulas estavam relacionadas umas às outras e objetivaram relacionar o conceito de indução eletromagnética aos de campo elétrico, campo magnético, carga elétrica, corrente elétrica, fluxo elétrico, circulação elétrica, força eletromagnética e taxa

\footnotetext{
${ }^{3}$ Os rótulos para cada passo, postos em parênteses, foram criados por nós para facilitar a referência.
} 
de variação temporal. O quadro 1 é uma linha do tempo que sintetiza esse processo.

Quadro 1 - Linha do tempo das UEPS em termos dos passos (P) e das aulas (A).

\begin{tabular}{|c|c|c|}
\hline Passo & Descrição & Aulas \\
\hline 1 & Seleção de conteúdo & 0 \\
\hline 2 & Emergência de conhecimento prévio & 1 \\
\hline 3 & Problematização do conhecimento prévio & 1 \\
\hline 4 & Diferenciação progressiva & $2,3,4,5$ \\
\hline 5 & Reconciliação integrativa & 6,7 \\
\hline 6 & Diferenciação integrativa & 8 \\
\hline 7 & Avaliação somativa & 9 \\
\hline 8 & Avaliação das UEPS & $\mathrm{X}$ \\
\hline
\end{tabular}

Cada aula durou uma hora e 40 minutos e foi repartida em dois períodos, o primeiro com 40 minutos, no qual o professor apresentava o conteúdo na sua forma final de maneira expositivo-dialogada. No segundo, que levava uma hora, o professor propunha problemas para serem resolvidos pelos alunos em grupos (três a quatro pessoas). O primeiro dos períodos é referido como aula expositivo-dialogada (AE) e o segundo é chamado de resolução de problemas (RP). Houve uma exceção na primeira aula, pois a RP foi realizada antes da AE.

Os objetivos das AE eram o de guiar a construção significativa de novo conhecimento na etapa predicativa e de tornar mais fácil a organização conceitual das estruturas cognitivas. Nestas, os princípios programáticos da diferenciação progressiva, da reconciliação integradora e da organização sequencial foram aplicados por meio de uso de instrução verbal e uso de mapas conceituais. Por outro lado, os objetivos das RP eram os de estimular o pensamento recursivo e operatório, facilitar a manipulação de conhecimento em situação, além de prover condições para os estudantes tomarem consciência dos seus invariantes operatórios. Nestas, a apresentação de situações-problema foi desenvolvida por meio da resolução dos problemas apresentados pelo professor.

Um texto de apoio contendo o conteúdo das aulas foi construído para que os estudantes usassem quando julgassem necessário ${ }^{4}$. Tratava-se de um texto de referência primário para que os alunos pudessem revisitar o conteúdo abordado nas aulas, mas que não esgotava as possibilidades de estudo. Além desta produção, o material proposto para estudo envolvia livros didáticos tradicionais de Física ${ }^{5}$, bem como artigos e problemas extraídos de revistas especializadas da área de Ensino de Física. Isto foi feito para buscar o aspecto transversal da diversidade de materiais didáticos (MOREIRA, 2011).

\footnotetext{
4 O autor terá satisfação em disponibilizá-lo via email (glaucopantoja@hotmail.com)

${ }^{5}$ Um exemplo de livro didático tradicional de Física é a obra de Nussenzveig (2006).
} 
As diferenças epistemológicas e ontológicas entre os conceitos de força e de campo já haviam sido amplamente discutidas durante o curso e já estavam sendo sedimentadas (MARTIN; SOLBES, 2001; FURIÓ; GUISASOLA; ZUBIMENDI, 1998). Cabe aqui ressaltar que a ênfase dada para o conceito de campo eletromagnético é a da simetria entre os campos elétricos e magnéticos, pois comumente concebe-se indução eletromagnética somente como indução de campos elétricos rotacionais a partir de campos magnéticos dinâmicos (lei de Faraday). Aqui, enfatiza-se também o processo reverso, o de campos magnéticos rotacionais serem produzidos por campos elétricos dinâmicos (lei de Ampère-Maxwell).

As UEPS iniciaram com a emergência de conhecimento prévio (passo 2), que buscou uma avaliação diagnóstica, respeitando o princípio de que a variável isolada mais importante a influenciar a aprendizagem significativa é o conhecimento prévio. Assim, os estudantes tinham possibilidade de externar seus conhecimentos prévios ou utilizá-los em ação na avaliação diagnóstica. No final da unidade foi aplicada, também, uma avaliação somativa para avaliar possíveis produtos significativos de aprendizagem construídos individualmente durante as UEPS (passo 7). A avaliação formativa foi realizada durante toda a unidade didática. A partir das respostas às avaliações diagnóstica, formativa e somativa dessa UEPS, dos modos de conceitualização evidenciados das UEPS anteriormente aplicadas em magnetostática (PANTOJA; MOREIRA, 2019) e em eletrostática (PANTOJA; MOREIRA, 2020), e de concepções já registradas na literatura, pudemos construir certas inferências sobre os modos de conceitualização inicialmente usados por eles para abordar o conceito de indução eletromagnética nesta primeira avaliação.

Na aula 1, a RP envolveu uma atividade com quatro questões, sendo uma de múltipla escolha (lei de Ampère-Maxwell), com justificativa, e três dissertativas (lei de Faraday). Na AE, foi feita uma abordagem histórico-filosófica ao conteúdo, a partir da visão geral da construção do conceito de indução eletromagnética. Foram feitas perguntas para motivar a diferenciação progressiva nas aulas 2, 3,4 e 5, tais como: "como funcionam motores elétricos?" e "como ocorrem a produção e a propagação de ondas de rádio?".

Na aula 2, a AE incluiu a apresentação da lei de Faraday nas formas diferencial (rotacional) e integral (circulação), enquanto a RP consistiu em três situações-problema, uma envolvendo descrição de interações eletromagnéticas, uma sobre representação simbólica do campo eletromagnético e uma de cálculo de campo eletromagnético. Já na aula 3 , a AE visou a diferenciação progressiva entre fem de movimento e fem induzida por campos elétricos na lei de Faraday integral, bem como os mecanismos de produção de fem, ao mesmo tempo em que na RP houve a proposição de duas questões sobre representação simbólica do campo elétrico e uma sobre descrição de interação eletromagnética.

$\mathrm{Na}$ aula 4, mais uma diferenciação progressiva é feita na $\mathbf{A E}$, por meio da abordagem aos motores e geradores usando a lei de Faraday integral, enquanto na RP foram propostas três questões conceituais para descrever interações eletromagnéticas usando o conceito de corrente elétrica induzida. Na sequência, na aula 5, a AE objetivou a descrição da 
construção histórica do conceito de corrente de deslocamento, na qual foi possível abordar o fenômeno de indução de campos magnéticos a partir de campos elétricos variáveis (lei de Ampère-Maxwell), e a RP enfocou três questões sobre corrente de deslocamento, sendo duas para representar simbolicamente o campo eletromagnético e uma para calculá-lo.

Na aula 6, a AE apresentou a lei de Ampère-Maxwell comparada com a lei de Faraday, o que indica reconciliação integrativa ao mostrarmos diferenças e semelhanças entre as duas leis, e a RP trouxe duas questões envolvendo cálculos de campos eletromagnéticos. $\mathrm{Na}$ aula 7, a AE discutiu a interação eletromagnética e as fontes de campo eletromagnético de forma mais aprofundada que a 6 , através do contraste entre campos eletromagnéticos estáticos e dinâmicos, houve ainda a análise da equação de balanço de energia para o campo eletromagnético nas duas situações, o que tornou possível discutir explicitamente o papel estruturante das leis de Faraday e Ampère-Maxwell na interação eletromagnética. Não houve RP nessa aula.

Na aula 8, a AE objetivou a derivação da equação de onda eletromagnética e da velocidade da luz a partir das equações de Maxwell, o que tornou possível realizar uma diferenciação progressiva (introdução do conceito de onda eletromagnética) em uma perspectiva de reconciliação integrativa (vínculo com o restante do conteúdo e com as equações estruturantes do eletromagnetismo), porém não houve RP. A aula 9 não teve $\mathbf{A E}$ e na RP houve uma avaliação somativa individual com cinco questões, sendo duas sobre lei de Ampère-Maxwell e três sobre lei de Faraday-Lenz, e mais um mapa conceitual.

Discutimos na sequência os aspectos relativos aos métodos de análise de dados (passo 8), que objetivaram avaliar as UEPS. Ademais, descrevemos o contexto no qual a pesquisa foi aplicada, os instrumentos adotados para a coleta dos dados, bem como os processos metodológicos de interpretação destes durante a realização da investigação.

\section{III.2 Metodologia investigativa}

Houve aplicação do estudo em dois contextos distintos, ambos em universidades brasileiras, uma da região Sul do Brasil (estudo I) e outra da região Norte (estudo II). O grupo do estudo I era constituído por 17 estudantes dos cursos de Bacharelado e de Licenciatura em Física, com faixa etária entre 19 e 29 anos, matriculados pela primeira vez em uma disciplina de Física Geral III. O grupo do estudo II era composto de 12 alunos de mesma faixa etária do primeiro grupo e havia cursado componentes curriculares semelhantes, mas estavam matriculados em um curso de Engenharia Física. Nove décimos da última turma haviam sido reprovados no curso de Física $\mathrm{I}^{6}$ e afirmavam sentir-se frustrados com o mau

\footnotetext{
6 Trata-se obviamente de um processo de corresponsabilidade. Não se trata de achar culpados, mas de apontar para aspectos possivelmente limitantes que influenciaram nas escolhas didáticas durante o percurso.
} 
andamento da constituição do curso que faziam ${ }^{7}$, o que conferiu um fator desmotivador para os alunos desde o início do curso.

$\mathrm{Na}$ época da coleta de dados, a Universidade na qual o estudo I foi desenvolvido não requeria a submissão do projeto de pesquisa (de doutorado, no caso) a uma comissão de ética para pesquisa em humanos, pois esse tipo de julgamento era feito no âmbito da comissão de pós-graduação do curso. No caso do estudo II, a Universidade em que foi desenvolvido sequer possuía uma comissão de ética para pesquisa com humanos, portanto, para garantir a aplicação de procedimentos éticos de pesquisa, convidamos os participantes a integrar a investigação como sujeitos, esclarecemos que a pesquisa não lhes garantiria benefícios ou malefícios, apontamos que a participação no estudo era voluntária e que poderiam abandonar a investigação quando bem entendessem, sem que lhes fosse implicado qualquer ônus, além de indicarmos que não haveria compromisso financeiro entre qualquer das partes. Por fim, passamos um Termo de Consentimento Livre e Esclarecido, contendo esse conteúdo descrito, para que assinassem em caso de concordância. Nenhum estudante declinou da participação na investigação durante todo o processo.

Os estudantes de ambos os grupos já haviam estudado conteúdos de disciplinas de Física Geral I (mecânica) e Física Geral II (ondas, fluidos, oscilações e termodinâmica). Assim, julgamos possível partir da premissa de que os estudantes tinham ideias relativamente consolidadas sobre força e sobre energia, além de conhecimento relevante sobre o conceito de campo gravitacional. Levando isto em consideração, construiu-se uma UEPS para introduzir os conceitos de campo vetorial e campo escalar, como uma preparação para as UEPS seguintes sobre campo elétrico e sobre campo magnético. Buscou-se adequar as UEPS para cada caso sempre que possível, pois os contextos guardavam diferenças claras. As UEPS descritas aqui se enquadram no final do curso de Física Geral III.

Os principais instrumentos de coleta de dados envolviam mapas conceituais dos estudantes, respostas dos problemas de lápis e papel produzidas nas RP e notas de campo produzidas pelo pesquisador. A partir disto, comparamos evidências empíricas (análise dos registros textuais) com as possíveis respostas produzidas a partir de um modo de conceitualização. Para realizar a análise dos registros textuais, empregou-se os princípios da análise de conteúdo (BARDIN, 2008). Neste trabalho, analisamos prioritariamente as respostas aos problemas de lápis e papel. Os mapas conceituais e notas de campo produzidos foram usados como ferramentas de triangulação para solucionar dúvidas ou falsear hipóteses que surgissem no processo de análise.

A análise de conteúdo propõe a facilitação na interpretação e diminui incertezas na tomada de inferências feita na leitura de registros textuais. Ela tem uma função heurística no processo de sistematização da coleta de informação das mensagens e se configura como uma

\footnotetext{
${ }^{7}$ Comunicação pessoal com o então coordenador do programa de Ciência e Tecnologia da Universidade e com os próprios estudantes da turma. Havia dificuldade na constituição de laboratórios, estágios, registro em conselho da área que poderiam limitar o futuro desenvolvimento profissional dos alunos.
} 
alternativa à leitura "intuitiva". Ela pode ser compreendida como um conjunto de técnicas analíticas que visam realizar inferências sobre as condições de produção ou recepção das mensagens e toma como base indicadores obtidos via procedimentos objetivos e sistemáticos de descrição do conteúdo de mensagens (BARDIN, 2008).

Um ciclo de análise de conteúdo possui três etapas: a pré-análise, a exploração do material e a realização de inferências. A pré-análise envolve: a leitura inicial do material; a seleção do corpus, respeitando as regras da homogeneidade (os materiais são semelhantes), da exaustividade (todas as tarefas foram analisadas), da pertinência (as tarefas são igualmente relevantes) e da representatividade (o material é representativo do todo); a construção de hipóteses; a produção de índices e indicadores; a preparação do material para a sua posterior exploração. A exploração do material subentende a aplicação das decisões tomadas na etapa anterior, além da implementação das operações de codificação, decomposição e enumeração. A tomada de inferências inclui a interpretação e o tratamento dos resultados, o que implica em uma leitura mais elaborada e sintética que a inicial. Na sequência descrevemos como cada uma destas etapas foi implementada.

Na pré-análise, para satisfazer a regra da homogeneidade, adotamos como corpus da investigação cinco das sete tarefas contendo problemas de lápis-e-papel (não houve RP nas aulas 7 e 8), já que duas delas estavam orientadas a situações de cálculo de campo eletromagnético, algo fora do escopo deste trabalho. As regras de pertinência, exaustividade e representatividade foram satisfeitas, pois foram consideradas todas as atividades ligadas ao objeto de estudo, a saber, conceitualização em situações de representação simbólica do campo eletromagnético e de descrição de interações eletromagnéticas. Na leitura flutuante, buscamos por índices e indicadores relacionados aos invariantes operatórios explícitos (na escrita) e implícitos (que unem lacunas na escrita) recorrentes nas tarefas dos alunos. Conduzimos tal estágio de forma a relacionar o que os alunos escreviam ou deixavam de escrever com dados da literatura de pesquisa em Ensino de Física sobre concepções relativas ao conceito de campo eletromagnético. Disto, criou-se um rol de possíveis teoremas-em-ação representativos das respostas dos estudantes para conduzir a exploração do material;

A exploração do material objetivou organizar os teoremas-em-ação evidenciados pelos alunos em possíveis modos de conceitualização. Na sequência, buscou-se indícios dando suporte ao uso dos modos. Inicialmente, identificamos a relação entre a pergunta proposta e a resposta apresentada pelos estudantes, o que permitiu vincular as metas das situações aos objetivos elaborados pelos alunos. Após isto, foram marcados os invariantes operatórios associados a estes objetivos nas respostas dos alunos. Em seguida, foram organizados os trechos explicitados pelos alunos a fim de reconstituirmos inferências possivelmente realizadas por eles. $\mathrm{Na}$ sequência, foram analisadas as relações entre as proposições explícitas de modo a podermos inferir teoremas-em-ação e conceitos-em-ação implícitos que dariam sentido às relações, mas que por alguma razão não são mencionados. Por fim, construímos diagramas hipotéticos de raciocínio contendo regras de ação do tipo 
SE... ENTÃO organizando os invariantes operatórios implícitos e explícitos compatíveis com os encadeamentos de ideias apresentados na resposta apresentada. Em toda a análise a frase foi usada como unidade de análise e os enunciados foram tomados como unidade de contexto (situação proposta e resposta do estudante);

A tomada de inferências é caracterizada pela interpretação da evolução da aplicação dos modos de conceitualização dos estudantes ao longo da UEPS às situações, o que gerou um diagrama sintético apresentado na seção de resultados. Isto nos foi útil para entender que mudanças ou que estabilizações ocorreram na conceitualização dos estudantes.

A metodologia abordada aqui seguiu moldes idênticos à empregada por Pantoja e Moreira $(2020,2019)$ para analisar a conceitualização de estudantes de nível superior sobre os conceitos de campo elétrico e campo magnético. Na sequência apresentamos os resultados de acordo com as etapas da análise de conteúdo.

\section{Resultados}

Apresentamos os resultados das etapas de pré-análise, de exploração do material e de tomada de inferências desenvolvidas na análise de conteúdo. Na primeira, trazemos uma lista de teoremas-em-ação (proposições) e de conceitos-em-ação (categorias) possivelmente utilizados pelos alunos; na segunda, a organização destes invariantes operatórios em modos de conceitualização, e na terceira, discutimos como foram aplicados os modos de conceitualização nas situações propostas durante a UEPS para analisar como se deu a conceitualização nas unidades. Entre a segunda e a terceira etapa, introduzimos um exemplo de como foi desenvolvida a análise. Para uniformizar a notação, utilizamos maiúsculas para situações e minúsculas para modos de conceitualização e invariantes operatórios (para os dois casos lança-se mão dos alfabetos grego e latino).

\section{IV.1 Pré-análise}

Para sistematizar a investigação foi necessário descrever como os alunos mobilizam seus invariantes operatórios em situação. Por haver diferentes tipos de situação na teoria eletromagnética seria preciso classificá-las. Com base em trabalho que visa construir um campo conceitual do campo eletromagnético (PANTOJA, 2021), trazemos duas classes de situações que dão sentido ao conceito de campo eletromagnético, são elas a descrição de interações eletromagnéticas $(\Sigma)$ e a representação simbólica do campo eletromagnético $(\Theta)$. Cada uma delas é estruturada de forma diferente e solicita a mobilização de invariantes operatórios de distintas dimensões.

A classe de descrição de interações eletromagnéticas $(\Sigma)$ requer o estabelecimento de referência a situações nas quais haja interações entre objetos eletricamente carregados em movimento arbitrário (sistemas de cargas e correntes) e campos elétricos ou magnéticos dinâmicos (ou ambos). É sempre necessário descrever a maneira pela qual estes objetos 
interagem mediados por campos elétricos e/ou magnéticos, mesmo que a fonte seja omitida. Trazemos um exemplo de enunciado de situação desse tipo:

Suponha que você tenha um campo magnético uniforme (com respeito à posição), $\vec{B}$, limitado a um volume cilíndrico de raio $R$. Esse campo magnético está decrescendo em intensidade a uma taxa constante ao longo do tempo. Qual a aceleração instantânea de uma carga negativa de valor $q$ nas regiões $r<R$ e $r>R$ ?

Para resolver este problema e similares, é preciso identificar os objetos interagentes (1). É preciso compreender a interação entre os objetos como tendo natureza eletromagnética, ou seja, é necessário considerar campos e forças eletromagnéticas (2). É necessário aplicar leis para descrever trocas de momentum e/ou de energia realizadas na interação (3). Por último, é imprescindível descrever a dinâmica do portador de carga elétrica de prova (4).

No exemplo apresentado, o estudante precisa: identificar a fonte de campo magnético e a carga elétrica negativa como objetos interagentes (1); fazer considerações sobre o campo magnético e determinar a existência de um campo elétrico induzido (2); aplicar a força de Lorentz para determinar a força resultante sobre o portador de carga elétrica negativa (3); descrever a dinâmica desta carga de prova através de invariantes operatórios da mecânica clássica (4). Dividimos as quatro operações de pensamento em dimensões para melhor analisar o emprego dos invariantes operatórios por parte dos alunos. Esta divisão é apresentada no quadro 2 .

Há, obviamente, outras possibilidades. Pode-se, por exemplo, retirar o campo magnético e colocar um campo elétrico variável no lugar, junto com a retirada de uma carga em repouso e introdução de uma carga elétrica pontual em velocidade constante (ou mesmo variável), apresentar problemas abertos, ou questões com solução não exata, etc. Deve-se sempre ter uma fonte de campo elétrico ou campo magnético variável e um objeto dotado de carga elétrica.

Para a classe de situações $\Sigma$, temos os seguintes invariantes operatórios: $a_{1}$ ) as fontes do campo eletromagnético são portadoras de carga elétrica em movimento ${ }^{8}$ e campos elétricos ou campos magnéticos variáveis no tempo; $b_{1}$ ) Os campos eletromagnéticos são fluidos; $b_{2}$ ) Os campos eletromagnéticos são grandezas físicas reais e materiais; $b_{3}$ ) Os campos eletromagnéticos são ferramentas matemáticas; $b_{4}$ ) Os campos eletromagnéticos são reais e imateriais; $c_{1}$ ) A força eletromagnética é exercida instantaneamente à distância; $c_{2}$ ) A força eletromagnética é transmitida contiguamente pelo espaço; $c_{3}$ ) Os campos eletromagnéticos são suportes para a transferência de energia; $c_{4}$ ) Os campos eletromagnéticos representam a força por unidade de carga elétrica sobre um portador de carga elétrica; $c_{5}$ ) Os campos eletromagnéticos transferem momentum e energia por execução de força e realização de trabalho; $d_{1}$ ) A força eletromagnética é igual ao campo

\footnotetext{
${ }^{8}$ Aqui, quer-se dizer movimento ordenado, ou seja, correntes elétricas.
} 
eletromagnético; $d_{2}$ ) A força eletromagnética é diferente do campo eletromagnético; $e_{1}$ ) A energia eletromagnética localiza-se em portadores de carga em movimento; $e_{2}$ ) A energia eletromagnética está nos portadores de carga elétrica em movimento e é trocada pelo campo eletromagnético; $e_{3}$ ) A energia cinética dos portadores de carga elétrica em movimento é transformada em energia de interação do campo eletromagnético; $f_{1}$ ) A força eletromotriz induzida é produzida por uma força magnética quando há movimento de um condutor em uma região de campo magnético estacionário; $f_{2}$ ) A força eletromotriz induzida é estabelecida através de uma força elétrica exercida por campo elétrico induzido quando em uma região de campo magnético variável; $f_{3}$ ) A força eletromotriz induzida é produzida por uma variação temporal de fluxo magnético quando há movimento de um condutor em uma região de campo magnético estacionário; $g_{1}$ ) Os campos elétricos realizam trabalho sobre portadores de carga elétrica móveis; $g_{2}$ ) Os campos magnéticos não realizam trabalho sobre portadores de carga elétrica móveis; $h_{1}$ ) As trocas de energia na interação eletromagnética são instantâneas; $h_{2}$ ) As trocas de energia na interação eletromagnética são não instantâneas; $i_{1}$ ) As forças eletromagnéticas satisfazem ao princípio da superposição; $i_{2}$ ) Os campos eletromagnéticos sofrem colisões; $i_{3}$ ) Os campos eletromagnéticos satisfazem ao princípio da superposição.

A classe de representação simbólica do campo $(\Theta)$ requer que os sujeitos estabeleçam relações abstratas e relacionais entre campo eletromagnético e outros conceitos relevantes a fenômenos de indução eletromagnética. Representações simbólicas não guardam relação estrutural com o objeto que visam representar (MARKMAN, 1999).

Quadro 2 - Descrição das dimensões para análise de invariantes operatórios da classe de situações.

\begin{tabular}{|c|l|c|}
\hline D & \multicolumn{1}{|c|}{ Descrição } & I. operatórios \\
\hline 1 & A - Identificação de fontes de campo eletromagnético & $a_{1}$ \\
\hline \multirow{4}{*}{2} & B - Descrição da natureza ontológica do campo eletromagnético & $b_{1}, b_{2}, b_{3}, b_{4}$ \\
\cline { 2 - 3 } & C - Identificação do papel do campo na interação eletromagnética & $c_{1}, c_{2}, c_{3}, c_{4}, c_{5}$ \\
\cline { 2 - 3 } & D - Relação entre força eletromagnética e campo eletromagnético & $d_{1}, d_{2}$ \\
\hline \multirow{4}{*}{3} & E - Localização da energia eletromagnética & $e_{1}, e_{2}, e_{3}$ \\
\cline { 2 - 3 } & F - Identificação da natureza física do campo eletromagnético & $f_{1}, f_{2}, f_{3}$ \\
\cline { 2 - 3 } & G - Descrição de trocas energéticas & $g_{1}, g_{2}$ \\
\cline { 2 - 3 } & H - Consideração da finitude da velocidade da interação & $h_{1}, h_{2}$ \\
\cline { 2 - 3 } & I - Aplicação do princípio da superposição & $i_{1}, i_{2}, i_{3}$ \\
\hline 4 & Elementos provenientes do campo conceitual da mecânica clássica & \\
\hline
\end{tabular}

Para a representação simbólica do campo eletromagnético, os estudantes devem referir-se às fontes de campo (elétrico ou magnético), em primeiro lugar. Então, devem estabelecer referência a pontos do espaço. Depois, é preciso referenciar os vetores campo 
elétrico e magnético (intensidade, direção e sentido). Apresentamos uma situação exemplar a seguir:

É possivel apresentar um exemplo de situação na qual seja possível afirmar, seguramente, que você tenha um campo elétrico induzido, devido à variação do campo magnético?

A resolução de problemas desta natureza necessita de identificação de fontes de campo eletromagnético (1). A solução requer enumeração e caracterização de pontos do espaço usando linguagem natural ou teoremas-em-ação da álgebra ou da análise vetorial (2), além de mapeamento do significado das equações de Maxwell (3). Os campos eletromagnéticos são descritos por campos vetoriais, então a associação de vetores a pontos do espaço (4) é fundamental. Por último, o estabelecimento da representação simbólica (5) deve ser realizado.

O exemplo proposto envolve um problema não estruturado e, por isso, não possui solução única. É necessário identificar uma fonte de campo magnético, que pode ser uma fonte de corrente elétrica que varie lentamente, um solenoide, por exemplo (1). Devemos pensar em pontos do espaço para podermos construir uma curva amperiana (2) e precisamos mapear o significado da lei de Faraday nesta situação (3). Tal significado é o de que campo magnético variável é fonte de campo elétrico induzido, mas não só ele, é necessário buscar na lei de Ampère-Maxwell o significado de que corrente elétrica produz campo magnético. É preciso pensar em vetores campo elétrico induzido para relacioná-los à circulação do campo elétrico e à variação de fluxo magnético na lei de Faraday integral ou associá-los à derivada parcial do campo magnético e ao rotacional do campo elétrico na versão diferencial da lei (4). Por último, deve-se concluir que este arranjo é suficiente para produzir o fenômeno e descrevê-lo (5). Assim como fizemos para a classe de situações $\Sigma$, dividimos as operações de pensamento em dimensões para facilitar a análise. Os resultados estão apresentados no quadro 3.

Para a classe de situações $\Theta$, temos os invariantes operatórios a seguir: $k_{1}$ ) O fluxo elétrico é igual ao campo elétrico; $k_{2}$ ) O fluxo magnético é irrelevante, pois é nulo; $k_{3}$ ) Os campos elétricos devem ter componente irrotacional; $k_{4}$ ) Os campos magnéticos são solenoidais; $k_{5}$ ) Os campos elétricos são monopolares quando criados por carga elétrica; $k_{6}$ ) Os campos magnéticos nunca são monopolares; $l_{1}$ ) A circulação magnética é igual ao campo magnético; $l_{2}$ ) A circulação elétrica é igual ao campo elétrico; $l_{3}$ ) Os campos elétricos devem ter componente solenoidal; $l_{4}$ ) Os campos magnéticos são solenoidais; $l_{5}$ ) O campo elétrico é criado por campo magnético variável no tempo; $l_{6}$ ) O campo magnético é criado por correntes elétricas; $\left.l_{7}\right)$ O campo magnético é criado por campo elétrico variável no tempo; $m_{1}$ ) O fluxo é igual à componente normal do campo; $m_{2}$ ) O fluxo elétrico indica que o campo elétrico tem componente radial quando há portadores carga elétrica; $m_{3}$ ) O fluxo magnético indica que o campo magnético nunca tem componente radial; $m_{4}$ ) O fluxo elétrico 
indica a presença ou não de cargas elétricas produzindo campo elétrico numa região do espaço; $m_{5}$ ) O fluxo magnético indica a inexistência de cargas magnéticas produzindo o campo magnético no espaço; $n_{1}$ ) A circulação é igual à componente tangencial do campo; $n_{2}$ ) A circulação elétrica indica que os campos elétricos induzidos têm linhas de campo circulares; $n_{3}$ ) A circulação magnética indica que os campos magnéticos induzidos têm linhas de campo circulares; $n_{4}$ ) A circulação elétrica indica que campos magnéticos variáveis no tempo produzem campo elétrico induzido; $n_{5}$ ) A circulação magnética indica que corrente elétrica e campos elétricos variáveis no tempo produzem campo magnético induzido.

Quadro 3 - Descrição das dimensões para análise de invariantes operatórios da classe de situações.

\begin{tabular}{|c|l|c|}
\hline $\mathrm{D}$ & \multicolumn{1}{|c|}{ Descrição } & I. operatórios \\
\hline 1 & A - Identificação de fontes de campo eletromagnético & $a_{1}$ \\
\hline 2 & Elementos provenientes do campo conceitual da análise (matemática) & - \\
\hline \multirow{2}{*}{3} & $\mathrm{~K}$ - Interpretação física do fluxo elétrico e do fluxo magnético & $k_{1}, k_{2}, k_{3}, k_{4}, k_{5}$ \\
\cline { 2 - 3 } & $\mathrm{L}$ - Interpretação física da circulação elétrica e da circulação magnética & $l_{1}, l_{2}, l_{3}, l_{4}, l_{5}, l_{6}, l_{7}$ \\
\hline \multirow{2}{*}{4} & $\mathrm{M}$ - Relação entre fluxo e campo eletromagnético & $m_{1}, m_{2}, m_{3}, m_{4}, m_{5}$ \\
\cline { 2 - 3 } & $\mathrm{N}$ - Relação entre circulação e campo eletromagnético & $n_{1}, n_{2}, n_{3}, n_{4}, n_{5}$ \\
\hline 5 & Elementos provenientes do campo conceitual da análise (matemática) & - \\
\hline
\end{tabular}

Passamos ao segundo estágio de análise, no qual descrevemos os modos de conceitualização possivelmente utilizados pelos estudantes nas situações. Na sequência, apresentamos um exemplo de como os invariantes operatórios e modos de conceitualização foram esquematizados. É importante ressaltar que as duas listas de invariantes operatórios contêm tanto significados coerentes com visões sustentadas pelo conhecimento científico como alguns que não estão de acordo com a estrutura conceitual de referência científica. Ao longo da descrição dos resultados, argumentamos quais são os científicos e quais são os alternativos.

\section{IV.2 Exploração do material}

Buscamos organizar os invariantes operatórios em modos de conceitualização para entendermos melhor os processos de aprendizagem dos estudantes. Conforme destacado no referencial teórico, estes modos são estruturas descritivas do oportunismo e da contingência da conceitualização, e são úteis para descrever este processo em situações novas. Trata-se de formas de organização da ação em situação e envolvem a referência a estas por meio de conceitos. Produzimo-los a partir das respostas dos estudantes e de dados obtidos da revisão da literatura. 
Formulamos seis modos de conceitualização endereçados a situações de descrição de interações eletromagnéticas $(\Sigma)$ : ação instantânea a distância $\left(\sigma_{1}\right)$; campo eletromagnético fluido $\left(\sigma_{2}\right)$; campo eletromagnético como suporte $\left(\sigma_{3}\right)$; campo eletromagnético instrumentalista $\left(\sigma_{4}\right)$; campo eletromagnético científico-microscópico $\left(\sigma_{5}\right)$; e campo eletromagnético científico-macroscópico $\left(\sigma_{6}\right)$. Os invariantes operatórios associados a esses modos estão expressos no quadro 4.

Quadro 4 - Modos de conceitualização associados à descrição de interações eletromagnéticas.

\begin{tabular}{|c|c|c|c|c|c|c|c|c|c|}
\hline & $\mathrm{A}$ & $\mathrm{B}$ & $\mathrm{C}$ & $\mathrm{D}$ & $\mathrm{E}$ & $\mathrm{F}$ & $\mathrm{G}$ & $\mathrm{H}$ & $\mathrm{I}$ \\
\hline$\sigma_{1}$ & $a_{1}$ & & $c_{1}$ & $d_{1}$ & $e_{1}$ & & & $h_{1}$ & $i_{1}$ \\
\hline$\sigma_{2}$ & $a_{1}$ & $b_{1}$ & $c_{2}$ & $d_{2}$ & $e_{2}$ & & & $h_{2}$ & $i_{1}, i_{2}$ \\
\hline$\sigma_{3}$ & $a_{1}$ & $b_{2}$ & $c_{3}$ & $d_{2}$ & $e_{2}$ & & $g_{1}, g_{2}$ & $h_{2}$ & $i_{1}, i_{3}$ \\
\hline$\sigma_{4}$ & $a_{1}$ & $b_{3}$ & $c_{4}$ & $d_{2}$ & $e_{2}$ & $f_{1}, f_{2}$ & $g_{1}, g_{2}$ & $h_{2}$ & $i_{1}, i_{3}$ \\
\hline$\sigma_{5}$ & $a_{1}$ & $b_{4}$ & $c_{5}$ & $d_{2}$ & $e_{3}$ & $f_{1}, f_{2}$ & $g_{1}, g_{2}$ & $h_{2}$ & $i_{1}, i_{3}$ \\
\hline$\sigma_{6}$ & $a_{1}$ & $b_{4}$ & $c_{5}$ & $d_{2}$ & $e_{3}$ & $f_{3}$ & & $h_{2}$ & $i_{1}, i_{3}$ \\
\hline
\end{tabular}

Supôs-se que o nível de conceitualização das estruturas $\sigma$ aproximam-se progressivamente do conhecimento cientificamente aceito para a teoria do campo eletromagnético. $\mathrm{O}$ modo $\sigma_{1}$ admite a interação eletromagnética ocorrendo instantaneamente a distância, ou seja, um portador de carga elétrica ou condutor de corrente exerce força diretamente sobre o outro, sem influência de um campo eletromagnético. O modo $\sigma_{2}$ introduz o conceito de campo, porém em uma perspectiva ontológica e epistemológica substancialista (BACHELARD, 1996), isto é, o campo eletromagnético é fundamentalmente um fluido. O modo $\sigma_{3}$ difere do $\sigma_{2}$ na concepção de materialidade do campo, pois o primeiro se aproxima do éter cartesiano (WHITAKKER, 1910), um meio material de suporte para propagação da força. O modo $\sigma_{4}$ adota a perspectiva instrumentalista (BUNGE, 2010) para o campo eletromagnético, uma vez que o considera mera ferramenta matemática para cálculo da força eletromagnética. Os modos $\sigma_{5}$ e $\sigma_{6}$ são os mais próximos do científico, pois consideram o campo eletromagnético uma grandeza física real (transporta energia e momentum) e imaterial. Ambos diferem na abordagem: enquanto $\sigma_{5}$ inclui explicações microscópicas (usando campo e força), $\sigma_{6}$ abarca explicações macroscópicas (usando fluxo e fem).

Há, também, cinco classes relacionadas às situações de representação simbólica do campo eletromagnético $(\Theta)$, quais sejam: campo eletromagnético tautológico $\left(\theta_{1}\right)$; campo eletromagnético igual à equação de campo $\left(\theta_{2}\right)$; campo eletromagnético pictórico $\left(\theta_{3}\right)$; campo eletromagnético relacional $\left(\theta_{4}\right)$; campo eletromagnético integrado pictórico-relacional $\left(\theta_{5}\right)$. Os invariantes operatórios associados a esses modos estão expressos no quadro 5. 
Quadro 5 - Modos de conceitualização orientados à representação simbólica do campo eletromagnético.

\begin{tabular}{|c|c|c|c|c|c|}
\hline & $\mathrm{A}$ & $\mathrm{K}$ & $\mathrm{L}$ & $\mathrm{M}$ & $\mathrm{N}$ \\
\hline$\theta_{1}$ & $a_{1}$ & - & - & - & - \\
\hline$\theta_{2}$ & $a_{1}$ & $k_{1}, k_{2}$ & $l_{1}, l_{2}$ & $m_{1}$ & $n_{1}$ \\
\hline$\theta_{3}$ & $a_{1}$ & $k_{3}, k_{4}$ & $l_{3}, l_{4}$ & $m_{2}, m_{3}$ & $n_{2}, n_{3}$ \\
\hline$\theta_{4}$ & $a_{1}$ & $k_{5}, k_{6}$ & $l_{5}, l_{6}, l_{7}$ & $m_{4}, m_{5}$ & $n_{4}, n_{5}$ \\
\hline$\theta_{5}$ & $a_{1}$ & $k_{3}, k_{4}, k_{5}, k_{6}$ & $l_{3}, l_{4}, l_{5}, l_{6}, l_{7}$ & $m_{2}, m_{3}, m_{4}, m_{5}$ & $n_{2}, n_{3}, n_{4}, n_{5}$ \\
\hline
\end{tabular}

Supõe-se que o nível de conceitualização seja crescente. Os estudantes dominando $\theta_{5}$ sabem, basicamente, trabalhar com a formulação integral, tanto do ponto de vista simbólico como geométrico. $\mathrm{O}$ modo $\theta_{1}$ representa o conceito de campo eletromagnético sem estabelecer referência às equações de campo, somente se relaciona com as cargas elétricas. Já o modo $\theta_{2}$ o faz de maneira a confundir o campo eletromagnético com as equações de campo (ARAUJO; VEIT; MOREIRA, 2007; GUISASOLA et al., 2008). O modo $\theta_{3}$ representa simbolicamente o campo eletromagnético em uma perspectiva mais pictórica, em outras palavras, estabelece referência com maior ênfase à orientação dos campos elétrico e magnético. Em comparação com $\theta_{3}$, o modo $\theta_{4}$ destaca as relações entre campo eletromagnético e suas fontes (NOUSIANEN; KOPONEN, 2017), o que lhe confere caráter mais relacional. $\mathrm{O}$ modo $\theta_{5}$ envolve elementos das duas descrições anteriores, sendo o mais completo. Entende-se que tanto $\theta_{3} \operatorname{como} \theta_{4}$ são bons pontos de chegada para um curso de Física III, logo, consideramo-las equivalentes. No entanto, o ponto ótimo seria $\theta_{5}$.

\section{IV.3 Um exemplo}

Exibimos um exemplo de como o processo de análise foi desenvolvido para cada resposta de cada tarefa. A situação 1 da tarefa 4, que versa sobre transformação de energia, foi resolvida pelo aluno $\mathrm{F}$ do estudo $\mathrm{I}$. O enunciado requer a descrição de uma forma de transformar energia química da gordura em energia elétrica ${ }^{9}$. Tal situação pode envolver a descrição de uma interação eletromagnética, pois requer pelo menos dois elementos que interajam eletromagneticamente: uma fonte de campo magnético e um objeto condutor. Desta forma, a situação é da classe $\Sigma$.

Não existe solução fechada para este problema, pois ele é muito pouco estruturado (REF). Há duas formas de envolver o conceito de indução eletromagnética para abordar a situação e ambas envolvem o conceito de gerador. A primeira delas considera o rotor do gerador como fonte de campo magnético e o estator como bobina condutora de corrente,

\footnotetext{
${ }^{9}$ Deve ficar claro aqui que a ideia da questão foi usada em sentido amplo, pois não necessariamente a gordura é a fonte da energia química durante a pedalada. Em sentido estrito, os músculos podem, e costumam usar, energia provinda da quebra dos carboidratos alimentares ou endógenos.
} 
enquanto a outra envolve o processo reverso, ou seja, um condutor móvel e uma fonte de campo magnético fixa. A resolução será diferente para os dois casos se a abordagem for microscópica, mas é basicamente a mesma no caso macroscópico.

Ao escolhermos a abordagem microscópica, devemos estar conscientes de que no primeiro caso o campo magnético varia no tempo e induz um campo elétrico e no segundo não há campos elétricos induzidos, pois não há campos magnéticos variáveis no tempo. Com estes parâmetros, o movimento da espira é solidário ao dos portadores de carga e estes têm sua direção modificada pela força magnética, o que implica em uma fem do tipo Hall e, consequentemente, existe um campo elétrico equivalente que ajuda a resolver o problema (NUSSENZVEIG, 2006). Já na abordagem macroscópica, ambas as situações podem ser resumidas à análise da variação temporal do fluxo magnético. $\mathrm{O}$ estudante $\mathrm{F}$ realiza esta última escolha, conforme pode ser percebido em sua resposta:

Usando uma espira, uma bicicleta e um campo magnético. Para fazermos a roda da bicicleta, aplicamos um torque. Ao transmitirmos este torque à espira, faremos a mesma girar. Com isso ocorrerá uma variação no fluxo magnético e, consequentemente, uma fem induzida (bem como uma corrente elétrica induzida). Ou seja, além de queimarmos calorias, estaríamos gerando energia.

Os seguintes conceitos-em-ação explícitos são identificados em negrito na resposta: espira; campo magnético; roda; torque; giro; variação do fluxo magnético; fem induzida; corrente elétrica induzida; calorias; energia. O teorema-em-ação explícito a fem induzida é produzida por uma variação temporal de fluxo magnético quando há movimento de um condutor em uma região de campo magnético estacionário $\left(f_{3}\right)$ fica claro na resposta. $\mathrm{O}$ conceito de condutor é um conceito-em-ação implícito A análise de conhecimento predicativo se restringe a analisar somente os aspectos explícitos pelos estudantes em formas textuais, mas é possível ir além e levar em conta alguns elementos, conscientes ou inconscientes, implícitos na ação dos alunos enquanto resolviam esse problema. Tais informações podem ser inferidas a partir de lacunas deixadas no conhecimento explicitado por eles e são entendidos como invariantes operatórios implícitos.

Isto posto, que invariantes operatórios implícitos poderiam ser inferidos nesta análise? $\mathrm{O}$ aluno $\mathrm{F}$ afirma explicitamente na questão 2 desta mesma tarefa que "corrente elétrica produz campo magnético" e isto nos serviu como informação secundária para inferirmos pelo invariante operatório as fontes de campo eletromagnético são portadoras de carga elétrica em movimento e campos elétricos ou magnéticos variáveis $\left(a_{1}\right)$. Este invariante operatório aparece implícito na questão 1 , pois o estudante vincula uma fem a uma corrente elétrica induzida ao dizer que "...consequentemente uma fem induzida (bem como uma corrente elétrica induzida)", o que nos leva a concluir que como a espira é um condutor de corrente elétrica, então ela produz campo eletromagnético. 
O invariante operatório campos eletromagnéticos transferem momentum e energia por meio da execução de forças ou realização de trabalho $\left(c_{5}\right)$ resume praticamente a conclusão obtida pelo raciocínio do estudante. Vejamos:

Usando uma espira, uma bicicleta e um campo magnético. Para fazermos a roda da bicicleta, aplicamos um torque. Ao transmitirmos este torque à espira, faremos a mesma girar. Com isso ocorrerá uma variação no fluxo magnético e, consequentemente, uma fem induzida (bem como uma corrente elétrica induzida). Ou seja, além de queimarmos calorias, estaríamos gerando energia.

Está implícita na conceitualização do aluno que a energia química é primeiramente transformada em energia cinética (conceito-em-ação implícito) e que esta é transmitida à espira. O movimento da espira na região de campo magnético provoca uma variação de fluxo magnético ao longo do tempo, o que implica que o campo magnético está mediando a interação de fato. Isto produz uma fem induzida (e corrente elétrica) que se traduz em algo compatível com energia elétrica. $\mathrm{O}$ aluno conclui dizendo que no meio tempo de perdemos um tipo de energia (química) e ganhamos outro tipo (elétrica), é produzida energia cinética que está na espira (portador de cargas elétricas) e que é transformada por meio do campo eletromagnético. Por outro lado, o aluno não detalha como é a relação entre a força eletromagnética e o trabalho em questão (o que seria feito se usasse o modo $\sigma_{5}$ ).

Buscamos na questão 2 desta mesma tarefa que possível invariante operatório o aluno $\mathrm{F}$ poderia usar para a dimensão $\mathrm{D}$. O teorema-em-ação força eletromagnética é diferente do campo eletromagnético $\left(d_{2}\right)$ pode ser inferido, pois o aluno afirma que“... a corrente elétrica gerará um campo magnético que, afetando o ímã, gerará um torque”. Entendemos, portanto, que o estudante diferencia os dois conceitos, pois campo magnético pode aplicar torque, uma grandeza derivada da força.

Inferimos o invariante operatório a energia cinética dos portadores de carga elétrica em movimento é transformada em energia de interação do campo eletromagnético $\left(e_{3}\right)$ do mesmo raciocínio que inferimos $\left(c_{5}\right)$. Aqui a ênfase é na localização da energia e lá no papel do campo na interação. Ambas as dimensões são relevantes, pois não necessariamente o aluno supor que o campo medeia processos de troca energética implica garantir que ele suponha a energia presente no campo. Neste caso fica mais claro, mas há outros em que é difícil inferir.

$\mathrm{O}$ último invariante operatório sobre o qual discutimos é o da dimensão $\mathrm{H}$. O teorema-em-ação parece implícito na resposta do estudante, pois ele desenvolve uma linha causal de explicação para a troca de energia. $\mathrm{O}$ giro provoca mudança de fluxo, este induz uma fem e esta produz uma corrente elétrica, assim, achamos provável ele ter concebido o processo de maneira dinâmica, assim como tenta explicitá-lo. Apresentamos, a seguir, a "linearização" das operações de pensamento implícitas e explícitas adotadas por F em nossa análise através de regras de ação do tipo SE... ENTÃO: 
$\boldsymbol{S E}$ precisamos gerar energia elétrica aos custos de energia térmica, ENTÃO necessitamos transformar uma na outra. $\boldsymbol{S E}$ vamos consumir energia química da gordura, ENTÃO a transformaremos em energia cinética de rotação por meio de um torque. $\boldsymbol{S E}$ uma espira tem energia cinética de rotação \& $\boldsymbol{S} \boldsymbol{E}$ esta espira está em uma região de campo magnético, ENTÃOO ocorrerá variação temporal de fluxo magnético através da espira. SE há variação de fluxo magnético ao longo do tempo, ENTÃO é produzida uma fem induzida na espira. SE fem é produzida por energia, ENTÃO deve ser semelhante a ela. SE há fem induzida na espira \& SE a espira é um condutor de corrente elétrica, ENTÃO haverá produção de corrente na espira. SE há corrente elétrica na espira, ENTÃO foi-lhe transferida energia. SE esse processo é mediado por um campo magnético, ENTÃOO ele deve transportar energia.

Desta forma, concluímos que os teoremas-em-ação $a_{1}, c_{5}, d_{2}, e_{3}, h_{2}$ estão implícitos e o $f_{3}$ está explícito na conceitualização do aluno $\mathrm{F}$. Da análise do quadro 4, inferimos que o modo de conceitualização $\sigma_{6}$ foi usado por este aluno nesta situação. Não parece haver uma referência direta (explícita) ou indireta (implícita) estabelecida pelo aluno $\mathrm{F}$ com respeito ao aspecto ontológico que atribui ao campo magnético, logo preferimos não ir além na análise para a dimensão $\mathrm{B}$ para não corrermos o risco de forçarmos uma interpretação, pois a princípio admitimos que não há base empírica para interpretarmos a ocorrência de algum invariante operatório, explícito ou implícito, dessa dimensão nessa resposta do aluno. O princípio da superposição não se aplica para este caso, portanto, foi outra dimensão que não foi inferida por simplesmente não ser necessário referenciá-lo.

\section{IV.4 Tomada de inferências}

Neste trabalho, analisamos as evidências de uso de modos de conceitualização e as tomamos como indicadores de aprendizagem significativa, uma vez que esta envolve a aquisição não-arbitrária e não-literal de novos conhecimentos. Nem sempre produtos e processos significativos de aprendizagem envolvem conhecimentos corretos cientificamente. As concepções alternativas são exemplos disto, pois derivam de aprendizagem significativa a despeito de estarem cientificamente incorretas. Nesta seção, discutimos os diversos modos apresentados pelos alunos em situação e argumentamos que nas UEPS eles se aproximaram progressivamente de conhecimentos aceitos do ponto de vista científico. Escolhemos apresentar os resultados de cada aula para comparar os grupos dos dois estudos.

Os quadros 6 e 7 expõem um panorama dos modos de conceitualização evidenciados ao longo das UEPS sobre indução eletromagnética, nos estudos I e II, respectivamente. Neste quadro, usamos a letra T para indicar as tarefas propostas nas UEPS e o símbolo $S_{P}$ para a situação-problema em análise. Cada aluno é codificado por uma letra do alfabeto latino na segunda linha e cada célula contém o modo de conceitualização utilizado pelos estudantes em cada tarefa. Representamos os vieses cognitivos de redução funcional, fixação funcional e de 
erro conceitual pelas cores verde, azul e vermelho, respectivamente. Usamos espaços em branco para identificar uma questão não respondida. $\mathrm{O}$ quadro ter uma barra vertical dupla que separa os modos de conceitualização inferidos no estudo I (contexto sul-brasileiro) à sua esquerda e os dados análogos obtidos para o estudo II (contexto norte-brasileiro). Ambas as UEPS tiveram o mesmo professor.

Quadro 6 - Modos de conceitualização utilizados pelos alunos do estudo I.

\begin{tabular}{|c|c|c|c|c|c|c|c|c|c|c|c|c|c|c|c|c|}
\hline$T$ & \multicolumn{3}{|c|}{$A_{D}$} & \multicolumn{3}{|c|}{2} & 3 & \multicolumn{3}{|c|}{4} & \multicolumn{3}{|c|}{5} & \multicolumn{3}{|c|}{$A_{S}$} \\
\hline$S_{P}$ & 1 & 2 & 3 & 1 & 2 & 3 & 1 & 1 & 2 & 3 & 1 & 2 & 3 & 1 & 2 & 3 \\
\hline $\mathrm{A}$ & - & - & - & $\theta_{4}$ & $\sigma_{5}$ & - & \multirow[b]{2}{*}{$\mathrm{M}$} & $\sigma_{6}$ & $\sigma_{6}$ & $\sigma_{6}$ & - & $\theta_{4}$ & $\theta_{4}$ & $\theta_{4}$ & $\sigma_{4}$ & - \\
\hline B & $\sigma_{5}$ & $\sigma_{5}$ & - & $\theta_{4}$ & $\sigma_{5}$ & $\theta_{4}$ & & & $\sigma_{6}$ & $\sigma_{6}$ & $\theta_{4}$ & $\theta_{4}$ & $\theta_{4}$ & $\theta_{4}$ & $\sigma_{6}$ & $\sigma_{6}$ \\
\hline $\mathrm{C}$ & $\sigma_{5}$ & $\sigma_{5}$ & $\theta_{4}$ & $\theta_{4}$ & $\sigma_{5}$ & $\theta_{4}$ & \multirow{2}{*}{$\begin{array}{c}\text { A } \\
\text { I }\end{array}$} & $\sigma_{5}$ & $\sigma_{6}$ & $\sigma_{6}$ & - & - & - & $\theta_{4}$ & $\sigma_{6}$ & $\sigma_{6}$ \\
\hline D & $\sigma_{6}$ & $\sigma_{6}$ & - & $\theta_{4}$ & $\sigma_{5}$ & $\theta_{4}$ & & $\sigma_{6}$ & $\sigma_{6}$ & $\sigma_{6}$ & $\theta_{4}$ & $\theta_{4}$ & $\theta_{4}$ & $\theta_{4}$ & $\sigma_{6}$ & $\sigma_{6}$ \\
\hline $\mathrm{E}$ & - & $\sigma_{3}$ & - & $\theta_{4}$ & - & $\theta_{4}$ & \multirow{5}{*}{$\begin{array}{l}\mathrm{O} \\
\mathrm{R} \\
\mathrm{I} \\
\mathrm{A}\end{array}$} & $\sigma_{1}$ & $\sigma_{1}$ & - & - & - & - & - & $\sigma_{4}$ & $\sigma_{5}$ \\
\hline $\mathrm{F}$ & - & - & - & - & - & - & & $\sigma_{6}$ & $\sigma_{5}$ & $\sigma_{6}$ & $\theta_{4}$ & $\theta_{4}$ & $\theta_{4}$ & $\theta_{4}$ & $\sigma_{6}$ & $\sigma_{6}$ \\
\hline $\mathrm{G}$ & - & - & - & $\theta_{4}$ & $\sigma_{5}$ & $\theta_{4}$ & & $\sigma_{5}$ & $\sigma_{6}$ & $\sigma_{6}$ & $\theta_{1}$ & - & $\theta_{4}$ & $\theta_{4}$ & $\sigma_{6}$ & $\sigma_{6}$ \\
\hline $\mathrm{H}$ & $\sigma_{5}$ & $\sigma_{5}$ & - & $\theta_{4}$ & $\sigma_{5}$ & $\theta_{4}$ & & $\sigma_{6}$ & $\sigma_{1}$ & $\sigma_{6}$ & $\theta_{4}$ & $\theta_{4}$ & $\theta_{4}$ & $\theta_{4}$ & $\sigma_{6}$ & $\sigma_{6}$ \\
\hline $\mathrm{I}$ & $\sigma_{5}$ & $\sigma_{5}$ & - & $\theta_{4}$ & $\sigma_{5}$ & $\theta_{4}$ & & $\sigma_{6}$ & $\sigma_{1}$ & $\sigma_{6}$ & $\theta_{4}$ & $\theta_{4}$ & $\theta_{4}$ & $\theta_{4}$ & $\sigma_{6}$ & $\sigma_{6}$ \\
\hline $\mathrm{J}$ & - & $\sigma_{2}$ & - & $\theta_{4}$ & $\sigma_{5}$ & $\theta_{4}$ & $\mathrm{~F}$ & $\sigma_{6}$ & $\sigma_{6}$ & $\sigma_{6}$ & - & $\theta_{4}$ & $\theta_{4}$ & $\theta_{4}$ & $\sigma_{5}$ & $\sigma_{4}$ \\
\hline $\mathrm{K}$ & $\sigma_{6}$ & $\sigma_{5}$ & - & $\theta_{4}$ & $\sigma_{5}$ & $\theta_{4}$ & \multirow{4}{*}{$\begin{array}{l}\mathrm{A} \\
\mathrm{L} \\
\mathrm{T} \\
\mathrm{O}\end{array}$} & - & - & - & $\theta_{4}$ & - & - & $\theta_{4}$ & $\sigma_{4}$ & - \\
\hline $\mathrm{L}$ & - & $\sigma_{3}$ & - & $\theta_{4}$ & $\sigma_{5}$ & $\theta_{4}$ & & $\sigma_{5}$ & $\sigma_{6}$ & $\sigma_{6}$ & - & - & $\theta_{4}$ & $\theta_{4}$ & $\sigma_{4}$ & $\sigma_{6}$ \\
\hline $\mathrm{M}$ & - & - & - & $\theta_{4}$ & $\sigma_{5}$ & $\theta_{4}$ & & $\sigma_{6}$ & $\sigma_{1}$ & $\sigma_{6}$ & - & $\theta_{4}$ & $\theta_{4}$ & $\theta_{4}$ & $\sigma_{2}$ & $\sigma_{6}$ \\
\hline $\mathrm{N}$ & - & - & $\theta_{2}$ & $\theta_{4}$ & $\sigma_{5}$ & $\theta_{4}$ & & $\sigma_{6}$ & $\sigma_{1}$ & $\sigma_{6}$ & - & $\theta_{4}$ & $\theta_{4}$ & $\theta_{4}$ & $\sigma_{6}$ & $\sigma_{6}$ \\
\hline $\mathrm{O}$ & $\sigma_{6}$ & $\sigma_{4}$ & $\theta_{4}$ & $\theta_{4}$ & $\sigma_{5}$ & $\theta_{4}$ & \multirow{3}{*}{$\begin{array}{l}\mathrm{U} \\
\mathrm{U}\end{array}$} & $\sigma_{6}$ & $\sigma_{6}$ & $\sigma_{6}$ & - & $\theta_{4}$ & $\theta_{4}$ & $\theta_{4}$ & $\sigma_{5}$ & $\sigma_{4}$ \\
\hline $\mathrm{P}$ & $\sigma_{6}$ & $\sigma_{5}$ & $\theta_{4}$ & $\theta_{4}$ & $\sigma_{5}$ & $\theta_{4}$ & & $\sigma_{5}$ & $\sigma_{5}$ & $\sigma_{5}$ & - & $\theta_{4}$ & $\theta_{4}$ & $\theta_{4}$ & - & $\sigma_{6}$ \\
\hline Q & $\sigma_{3}$ & $\sigma_{3}$ & - & $\theta_{4}$ & $\sigma_{5}$ & $\theta_{4}$ & & $\sigma_{6}$ & $\sigma_{6}$ & $\sigma_{6}$ & - & $\theta_{4}$ & $\theta_{4}$ & $\theta_{4}$ & $\sigma_{4}$ & $\sigma_{4}$ \\
\hline
\end{tabular}

No caso específico dos vieses cognitivos, a redução funcional pode ser entendida como o ato de reduzir um fenômeno multicausal a uma única causa (VIENNOT; RAINSON, 1999) e a fixação funcional como a incapacidade de usar um objeto real ou de pensamento em uma função distinta da que admite ser a sua "função natural" (EYSENCK; KEANE, 1994). O erro conceitual se trata do uso de um determinado modo de conceitualização cientificamente aceito, mas com algum detalhe conceitual incorreto.

$\mathrm{Na}$ avaliação diagnóstica do estudo I (quadro 6), no que tange à única situação do tipo $\Theta$, alguns alunos parecem não mencionar o campo elétrico no espaço. Dois alunos $(\mathrm{C}$ e O) parecem utilizar um modo de conceitualização do tipo relacional $\left(\theta_{4}\right)$. Um aluno $(\mathrm{N})$ evidencia um viés de fixação funcional que o leva a utilizar um modo compatível com o que confunde campo e equações de campo $\left(\theta_{2}\right)$. Já o aluno $\mathrm{P}$ determina um campo elétrico usando 
a lei de Ampère para um contexto ao qual não se aplica, ou seja, o modo $\theta_{4}$ é adequado para dominar uma situação envolvendo o conceito de campo magnético estático, outro caso identificado como fixação funcional.

Quadro 7 - Modos de conceitualização utilizados pelos alunos do estudo II.

\begin{tabular}{|c|c|c|c|c|c|c|c|c|c|c|c|c|c|c|c|c|}
\hline$T$ & \multicolumn{3}{|c|}{$A_{D}$} & \multicolumn{3}{|c|}{2} & & \multicolumn{3}{|c|}{4} & \multicolumn{3}{|c|}{5} & \multicolumn{3}{|c|}{$A_{S}$} \\
\hline$S_{P}$ & & & & & & & & & & & & & & & & \\
\hline & $\sigma_{5}$ & $\sigma_{5}$ & & $\theta_{4}$ & $\sigma_{5}$ & $\theta_{4}$ & $\sigma_{6}$ & $\sigma_{6}$ & $\sigma_{6}$ & $\sigma_{6}$ & $\theta_{4}$ & $\theta_{4}$ & $\theta_{5}$ & $\theta_{4}$ & $\sigma_{6}$ & $\sigma_{6}$ \\
\hline & & & & $\theta_{4}$ & $\sigma_{5}$ & $\theta_{4}$ & $\sigma_{6}$ & $\sigma_{6}$ & $\sigma_{6}$ & $\sigma_{6}$ & $\theta_{4}$ & $\theta_{4}$ & $\theta_{5}$ & $\theta_{4}$ & $\sigma_{4}$ & $\sigma_{6}$ \\
\hline & $\sigma_{4}$ & $\sigma_{4}$ & $\theta_{4}$ & $\theta_{4}$ & $\sigma_{5}$ & $\theta_{4}$ & $\sigma_{6}$ & $\sigma_{6}$ & $\sigma_{6}$ & $\sigma_{6}$ & $\theta_{4}$ & $\theta_{4}$ & $\theta_{5}$ & $\theta_{4}$ & $\sigma_{5}$ & $\sigma_{5}$ \\
\hline & $\sigma_{3}$ & $\sigma_{3}$ & $\theta_{4}$ & $\theta_{4}$ & $\sigma_{5}$ & $\theta_{4}$ & $\sigma_{6}$ & $\sigma_{6}$ & $\sigma_{6}$ & $\sigma_{6}$ & $\theta_{4}$ & $\theta_{4}$ & $\theta_{5}$ & & & \\
\hline & $\sigma_{3}$ & $\sigma_{4}$ & & $\theta_{4}$ & $\sigma_{5}$ & $\theta_{4}$ & $\sigma_{4}$ & & & & $\theta_{4}$ & $\theta_{4}$ & $\theta_{4}$ & $\theta_{4}$ & $\sigma_{6}$ & $\sigma_{6}$ \\
\hline & $\sigma_{3}$ & $\sigma_{3}$ & $\theta_{4}$ & $\theta_{4}$ & $\sigma_{5}$ & $\theta_{4}$ & $\sigma_{6}$ & $\sigma_{6}$ & $\sigma_{6}$ & $\sigma_{6}$ & $\theta_{4}$ & $\theta_{4}$ & $\theta_{4}$ & $\theta_{1}$ & $\sigma_{6}$ & $\sigma_{6}$ \\
\hline & $\sigma_{3}$ & $\sigma_{3}$ & & $\theta_{4}$ & $\sigma_{5}$ & $\theta_{4}$ & $\sigma_{4}$ & & & & $\theta_{4}$ & $\theta_{4}$ & $\theta_{4}$ & $\theta_{4}$ & & \\
\hline & $\sigma_{5}$ & $\sigma_{5}$ & $\theta_{4}$ & $\theta_{4}$ & $\sigma_{5}$ & $\theta_{4}$ & $\sigma_{6}$ & $\sigma_{6}$ & $\sigma_{6}$ & $\sigma_{6}$ & $\theta_{4}$ & $\theta_{4}$ & $\theta_{4}$ & $\theta_{4}$ & $\sigma_{6}$ & $\sigma_{6}$ \\
\hline & $\sigma_{5}$ & $\sigma_{5}$ & & $\theta_{4}$ & $\sigma_{5}$ & $\theta_{4}$ & $\sigma_{4}$ & & & & $\theta_{4}$ & $\theta_{4}$ & $\theta_{4}$ & $\theta_{3}$ & $\sigma_{6}$ & $\sigma_{6}$ \\
\hline & $\sigma_{5}$ & $\sigma_{5}$ & & $\theta_{4}$ & $\sigma_{5}$ & $\theta_{4}$ & $\sigma_{6}$ & $\sigma_{6}$ & $\sigma_{6}$ & $\sigma_{6}$ & $\theta_{4}$ & $\theta_{4}$ & $\theta_{4}$ & $\theta_{1}$ & $\sigma_{6}$ & $\sigma_{6}$ \\
\hline & & & & $\theta_{4}$ & $\sigma_{5}$ & $\theta_{4}$ & $\sigma_{4}$ & & & & $\theta_{4}$ & $\theta_{4}$ & $\theta_{4}$ & $\theta_{4}$ & $\sigma_{6}$ & $\sigma_{6}$ \\
\hline
\end{tabular}

Com respeito às situações do tipo $\Sigma$, quatro alunos evidenciam modos de conceitualização do tipo científico-microscópico $\left(\sigma_{5}\right)$, três parecem apresentar do tipo campo científico-macroscópico $\left(\sigma_{6}\right)$, com um deles $(\mathrm{K})$ apresentando redução funcional na primeira questão. Por outro lado, na segunda situação, o aluno $\mathrm{J}$ parece usar o modo de conceitualização substancialista $\left(\sigma_{2}\right)$ e três alunos (E, L, Q) aparentam usar os do tipo suporte $\left(\sigma_{3}\right)$, pois representaram a situação como um transporte de corrente elétrica pelo campo magnético (THONG; GUNSTONE, 2008). Quatro alunos (I, P, H e K) possivelmente usam o viés da redução funcional, pois reduzem o problema à ação de um campo elétrico (I e P) ou à ação de um campo magnético (H e K). Além disto, é evidenciada a justaposição de modos de conceitualização (KALKANIS; HADZIDAKI; STAVROU, 2003) baseados tanto em conhecimento prévio externo (possivelmente obtido no Ensino Médio) quanto no abordado em UEPS anteriores sobre os campos elétrico e magnético. No que tange à situação do tipo $\Theta$ no estudo II (quadro 7), quatro alunos (C, D, F e H) parecem associar a existência de um campo elétrico a um campo magnético variável no tempo de maneira relacional $\left(\theta_{4}\right)$, algo diferente do primeiro estudo. De forma geral, estes estudantes parecem tentar estabelecer relação entre o que aprenderam e as situações apresentadas. Isto pode ser tomado como um indicativo de que processos significativos de aprendizagem ocorreram em UEPS anteriores.

No tocante à descrição da interação eletromagnética, há uma semelhança com o primeiro estudo: quatro alunos parecem apresentar o modelo $\sigma_{3}$, de campo como suporte de 
transporte de energia. Outra situação parecida é a referência ao campo magnético estático utilizado corretamente para situações inadequadas. Parece tratar-se de uma situação de fixação funcional dos alunos A, H, I e J, mas, ao mesmo tempo reflete um possível padrão de aprendizagem significativa na etapa operatória, pois eles usam teoremas-em-ação aprendidos para resolver problemas novos, mesmo em contextos distintos. Por outro lado, o aluno C parece atribuir importância meramente matemática ao campo eletromagnético $\left(\sigma_{4}\right)$.

Da análise da avaliação diagnóstica concluímos que os estudantes têm algum conhecimento prévio relevante relativo a experiências anteriores à disciplina, mas também se nota uma quantidade considerável que tenta utilizar o que aprenderam nas UEPS anteriores para resolver situações novas sem adaptar o conteúdo ao contexto da eletrodinâmica, o que leva a erros conceituais, epistemológicos e ontológicos, por mais que envolvam uso ativo de conhecimento prévio. Isso evidencia a necessidade de se chamar atenção para as diferenças entre aspectos estáticos e dinâmicos dos campos elétrico e magnético.

$\mathrm{Na}$ tarefa 2 respectiva ao estudo I (quadro 6), os alunos apresentam relações coerentes como o modo de conceitualização $\theta_{4}$, mais relacional e abstrato, na primeira e na terceira questões (classe $\Theta$ ). As diferenças entre as respostas estavam associadas à forma de organização da conduta expressa nas ideias e no seu grau de explicitação. Já na segunda questão (classe $\Sigma$ ), identificamos treze alunos dos dezessete dando sinais de uso do modelo $\sigma_{5}$. Por outro lado, cinco deles apresentaram erros procedimentais ${ }^{10}$ distintos $(\mathrm{B}, \mathrm{D}, \mathrm{H}, \mathrm{I}, \mathrm{N})$, dois deram indícios de redução funcional da redução da força eletromagnética à força magnética entre campo magnético e carga elétrica, inclusive computando-o usando a lei de Ampère inadequadamente $(\mathrm{G}$ e $\mathrm{M})$. Dois alunos não respondem à questão.

Com respeito ao estudo II (quadro 7), todos os estudantes evocaram modelos mais abstrato-relacionais para discutir o campo eletromagnético $\left(\theta_{4}\right)$ nas questões 1 e 3 . Com respeito à situação 2, o panorama é semelhante ao do estudo 1, a saber, sete alunos evidenciam uso de $\sigma_{5}$ e quatro utilizam este mesmo modo com viés de causalidade simples. Este viés se expressa quando eles atestam sobre a nulidade da força elétrica por não haver campo magnético no ponto onde está a carga elétrica de prova, um acaso de redução funcional.

Estes dados sugerem que as UEPS podem ter dado uma ênfase maior à representação simbólica do campo eletromagnético, pois os alunos tendem a estabelecer relações mais fortes e significativas com as fontes (NOUSIANEN; KOPONEN, 2017) em situações deste tipo. Destacamos aqui a importância de enfatizar as relações entre campo eletromagnético e sua orientação no espaço na mesma proporção para prover aos alunos maiores condições de construir modos de conceitualização mais integrados $\left(\theta_{5}\right)$.

\footnotetext{
10 Erros simples devido à fadiga, distração ou outro aspecto, que simplesmente são "automaticamente" sanados ao longo da produção textual. Por exemplo: esquecimento de um valor que volta na próxima linha da equação; colocação de um dois no lugar de um elevado ao quadrado que, no próximo passo volta a ser o que era antes do "erro". Não são erros conceituais.
} 
Na tarefa 3 do estudo I (quadro 6), mais de três quintos da turma faltou à aula. Alegaram terem se ausentado para estudar para uma prova dificílima de equações diferenciais. Entendemos que ocorram percalços no meio do caminho. Isto posto, entendemos ter sido necessário desconsiderar esta atividade, pois as respostas dos alunos presentes não seriam representativas das da turma.

Com respeito ao estudo II (quadro 7), quatro alunos parecem usar um modo de conceitualização mais instrumentalista $\left(\sigma_{4}\right)$, que toma o campo como ferramenta matemática. Tal modo descreve bem a interação eletromagnética, mas não leva em conta as nuances epistemológicas e ontológicas do conceito de campo eletromagnético. Por outro lado, sete evidenciam modos que usam o campo eletromagnético enfocando a variação temporal do fluxo magnético $\left(\sigma_{6}\right)$. Trata-se de um ganho considerável de aprendizagem se consideramos a evolução apresentada por estes estudantes.

$\mathrm{Na}$ tarefa 4 do estudo I, a segunda questão instigou os alunos a pensarem sobre o contratorque devido ao campo magnético gerado pela corrente induzida no estator sobre o rotor contendo um eletroímã, no caso do gerador elétrico. O conceito de campo magnético tem importância nesta situação, pois é responsável por oferecer este contratorque que se opõe à variação temporal do fluxo através do rotor, algo coerente com o princípio de conservação de energia. Cinco alunos descreveram a interação eletromagnética para esse sistema sem utilizar o conceito de campo eletromagnético (modo $\sigma_{1}$ ), o que entendemos como ponto preocupante. Por outro lado, os sete alunos que estiveram em aula equivalente no estudo II apresentaram indícios de usar o modo $\sigma_{6}$. Em nossa avaliação, isto foi um avanço.

A tarefa 5 do estudo I foi realizada antes da aula sobre corrente de deslocamento. Decidimos fazer isto para podermos analisar como os estudantes transfeririam conhecimento obtido sobre indução de campos elétricos a partir de campos magnéticos variáveis no tempo para o caso reverso (campos elétricos variáveis no tempo gerando campos magnéticos induzidos). A maior parte dos alunos pareceu evidenciar transferência para as situações 2 e 3 (classe $\Theta$ ), já que o conteúdo em questão se vinculava diretamente a outro já estudado e aprendido. Na segunda questão, 12 dos 17 alunos apresentaram respostas compatíveis com o modo de conceitualização $\theta_{4}$, já na terceira, foram 14 dos 17 . Por outro lado, na primeira questão, que perguntava o significado do conceito de corrente de deslocamento, 10 alunos não responderam, seis deram indícios de usar o modo $\theta_{4}$ e um pareceu utilizar $\theta_{1}$. Atribuímos a baixa adesão ao fato de o termo "corrente de deslocamento" ser potencialmente confuso para o contexto.

A mesma tarefa foi passada após a aula no estudo II. Na primeira e na segunda questões os 11 alunos deram sinais de uso na primeira questão modelos mais relacionais $\left(\theta_{4}\right)$. $\mathrm{Na}$ terceira questão, sete alunos aparentaram usar $\theta_{4}$ (relacional-abstrato) e quatro $\theta_{5}$ (integrado). Avaliamos este achado de forma positiva, pois há uma diferença apreciável com respeito ao estudo I e houve boa estabilização dos conceitos até o momento. Este dado dá 
corpo à hipótese de que o termo "corrente de deslocamento" pode causar confusão para os estudantes por ser desconhecido.

Na avaliação somativa do estudo I, 16 dos 17 alunos indicam sinais de uso de modos de conceitualização $\theta_{4}$ para situações da classe $\Theta$, o que evidencia capacidade de representar o campo eletromagnético estabelecendo referência a aspectos relacionais e abstratos, por exemplo, relação entre equações de campo, campo eletromagnético e fontes (NOUSIANEN; KOPONEN, 2017). Para situações da classe $\Sigma$, quatro dos estudantes apresentam conceitualização que varia entre modos de conceitualização mais instrumentalistas $\left(\sigma_{4}\right)$ e mais realistas $\left(\sigma_{5}\right.$ e $\left.\sigma_{6}\right)$. Três deles inclinam-se mais a modos microscópicos $\left(\sigma_{5}\right)$, enquanto um orienta-se mais a um modo macroscópico $\left(\sigma_{6}\right)$. Nove alunos tendem a uma estabilização em modos de conceitualização $\sigma_{6}$ e três em modos do tipo $\sigma_{4}$. Isto aponta que os estudantes podem ter desenvolvido um processo progressivo de domínio do conceito de campo eletromagnético, algo difícil de ser alcançado (ZUZA; GARCÍA; GUISASOLA, 2012).

Por outro lado, ocorrem alguns sinais de vieses cognitivos. Um exemplo é a confusão conceitual de associar um campo elétrico à variação de fluxo magnético quando o campo magnético é estacionário. Para situações deste tipo existe um campo elétrico equivalente atribuído ao efeito Hall em jogo (NUSSENZVEIG, 2006). Este é o responsável pela realização do trabalho, já que a força magnética não o faz. Outro caso de viés cognitivo é o da causalidade simples que se expressa quando um aluno considera a área de uma espira o único fato relevante para o cálculo da força magnética. Naturalmente, estes erros ocorrem durante o processo de aprendizagem e tanto a avaliação da inadequação quanto o feedback são importantes como forma de aprendizagem. Em nosso julgamento, estes estudantes estavam aptos a discutir estes aspectos conceituais, por conseguirem estabelecer referência ao real usando conceitos (VERGNAUD, 2009).

Para situações da classe $\Theta$ do estudo II, seis alunos aparentam usar o modo relacional $\left(\theta_{4}\right)$, dois estudantes abordam o campo eletromagnético através de aspectos gerais e sem estabelecer referência às equações de campo $\left(\theta_{1}\right)$, enquanto um aluno apresenta erro conceitual que relaciona a variação temporal do fluxo à produção de um campo elétrico quando há em jogo um campo magnético estacionário. A lei de Faraday vincula a variação temporal do campo magnético à produção de um campo elétrico, o que está incluso na formulação integral; no entanto, quando há campos magnéticos estacionários pode haver variação de fluxo através da mudança na orientação do circuito ou na área varrida pelo seu movimento (ZUZA; GARCÍA; GUISASOLA, 2012). Um caso exemplar é o de geradores com uma fonte de campo magnético estacionário, quando o posicionamento de bobinas em movimento em regiões de campo magnético produz fem de movimento. Esta é uma razão pela qual o modo $\sigma_{5}$ acaba tendo vantagem sobre o $\sigma_{6}$ em situações como essa, pois com o primeiro não surge qualquer campo elétrico induzido por campo magnético variável e a explicação acaba sendo mais precisa. 
Para situações da classe $\Sigma$, oito alunos apoiam-se na ideia de variação de fluxo e na noção de corrente induzida para falar sobre o campo eletromagnético (modo $\sigma_{6}$ ), enquanto um utiliza modos mais microscópicos para falar da fem e da corrente elétrica induzida nas duas questões (modo $\sigma_{5}$ ). Sabe-se que os estudantes costumam ter pouca familiaridade com modelos dessa natureza e tendem a preferir explicações com variação de fluxo do campo ao invés das que evocam o conceito de força eletromagnética (ZUZA et al., 2014). Com base nos dados apresentados sobre os modos de conceitualização dos estudantes, consideramos positiva a evolução dos estudantes durante a avaliação somativa e ao longo das UEPS.

\section{Conclusões e discussão}

Nesta investigação visamos responder à seguinte questão de pesquisa: "como estudantes de nível superior desenvolvem processos de conceitualização em uma unidade de ensino potencialmente significativa abordando o conceito de indução eletromagnética?’. Para tal, aplicamos duas UEPS correlatas para ensinar o conceito de indução eletromagnética em duas turmas de Ensino Superior em dois contextos diferentes. Empregamos a teoria dos campos conceituais (VERGNAUD, 2009) e demos nossa contribuição ao quadro teórico desenvolvido pelo autor ao discutir o oportunismo e a contingência da conceitualização (FANARO; OTERO; MOREIRA, 2009) introduzindo a noção de modo de conceitualização. Discutimos e indicamos os avanços e os retrocessos dos estudantes destas turmas na conceitualização do conceito de indução eletromagnética. As classes de situações envolvidas no estudo foram as de representação simbólica do campo eletromagnético $(\Theta)$ e de descrição de interações eletromagnéticas $(\Sigma)$.

Os resultados apontaram ocorrer maior consolidação dos modos de conceitualização do tipo relacional-abstrato $\left(\theta_{4}\right)$ com respeito à classe de situações $\Theta$. Isso é um indicativo de os alunos terem adquirido maior familiaridade em relacionar de forma abstrata o conceito de indução eletromagnética aos de campo eletromagnético, fluxo elétrico, fluxo magnético, circulação elétrica, circulação magnética, carga elétrica e corrente elétrica. Consideramos este resultado exitoso, pois os alunos começaram o curso com conhecimento aparentemente superficial e alcançaram graus relativamente altos de conceitualização.

Em pesquisas correlatas nos contextos da eletrostática e da magnetostática foram identificadas dificuldades na identificação de fontes de campo eletromagnético e na relação destas com os campos elétrico e magnético (FURIÓ; GUISASOLA; ZUBIMENDI, 1998; GUISASOLA; ALMUDÍ; FURIÓ, 2005; NOUSIANEN; KOPONEN, 2017). Assim, partimos do princípio de que o domínio de representações simbólicas costuma ser mais difícil para os estudantes e ensinamos de acordo; portanto, as UEPS enfatizaram mais o aspecto relacional dos campos por supô-lo mais complexo de ser aprendido. Os resultados são favoráveis neste sentido, no entanto, maior facilidade no trato com representações analógicas em relação às simbólicas parece depender do indivíduo, ao invés de ser regra geral. Portanto, entendemos 
que uma abordagem profícua deve buscar a integração entre as representações analógicas e simbólicas para facilitar o alcance da construção de modos do tipo $\theta_{5}$.

A análise de dados indica que os alunos se livram paulatinamente das amarras dos vieses cognitivos na análise de situações do tipo $\Sigma$. O fato de a conceitualização destes estudantes situar-se nos polos mais avançados da conceitualização (modos $\sigma_{4}, \sigma_{5}$ e $\sigma_{6}$ ) é igualmente digno de destaque. Deste dado deriva um próximo problema de investigação, o de formular situações que provejam condições para estabelecimento de relação explícita entre as abordagens dos modos $\sigma_{5}$ e $\sigma_{6}$.

Em investigações sobre concepções de estudantes de nível Superior, identificou-se a tendência a um viés mais macroscópico para a conceitualização de estudantes (ZUZA et al., 2014), o que é corroborado neste trabalho. Em outras pesquisas se aponta que os alunos têm dificuldade em entender o campo como grandeza física além de uma ferramenta matemática (FURIÓ; GUISASOLA; ZUBIMENDI, 1998; GUISASOLA; ALMUDÍ; FURIÓ, 2005). Apontamos que a concepção é resistente à mudança, pois insistimos fortemente na discussão de aspectos ontológicos e epistemológicos do campo eletromagnético como mediador da interação e, mesmo assim, o modo $\sigma_{4}$ é recorrente. Por outro lado, os alunos conseguem entender que força e campo eletromagnéticos são grandezas distintas, que a primeira depende das cargas de prova e de fonte, que o último é função de ponto e que não precisa necessariamente haver paralelismo entre o vetor que descreve a força e o que representa o campo, como no caso do campo eletrostático. Vemos que os avanços no domínio de um campo conceitual são progressivos se colocamos o problema nesta perspectiva.

Um caso que chamou bastante atenção no estudo I foi o de um aluno (M) que na última aula voltou a evidenciar um modo de conceitualização do tipo $\sigma_{2}$ (substancialista). Isto não é grande surpresa, pois dados deste tipo são discutidos desde a época em que a mudança conceitual começou a ser pesquisada. Sobre isto, podemos dizer que aprender significativamente envolve modificação dos significados antigos e construção de novas estruturas que coexistem com conhecimentos prévios, inclusive concepções alternativas, em perfis conceituais evocados em contextos socioculturais distintos (MORTIMER, 1996). Ademais, conceitualização é fortemente dependente das situações que dominamos e frequentemente agrega elementos incoerentes uns com os outros (VERGNAUD, 2009). Isto recai no estudante $\mathrm{M}$, pois ele parece voltar a utilizar um modo do tipo $\sigma_{2}$ na última aula do semestre. Este fenômeno nos mostra claramente a afirmação de Vergnaud sobre o domínio de um campo conceitual demandar tempo de ordem de grandeza que varia de anos a décadas (VERGNAUD, 2013). A aprendizagem significativa é, então, um processo não-linear, pois envolve constantemente avanços e retrocessos, rupturas e continuidades.

Outro aspecto que gostaríamos de destacar é motivacional. Ambas as turmas estavam cursando a disciplina de Física III novamente e, mesmo assim, apresentavam quase completo desconhecimento do conteúdo e raciocínio fragmentado sobre a temática na avaliação diagnóstica. Em especial no estudo II, os alunos se mostravam bastante desmotivados e 
elencaram várias razões para isto: metodologias ortodoxas que acabavam por enfatizar a aprendizagem mecânica; problemas com a constituição do curso na Universidade; ausência de laboratórios; falta de professores; falta de clareza na matriz curricular e no projeto pedagógico de curso. No fim do curso, muitos dos alunos atestaram ao professor terem ficado extremamente satisfeitos com a aprendizagem que desenvolveram na disciplina e lhe solicitaram que lecionasse a Física IV.

Por fim, destacamos como contribuição para a área de Ensino de Ciências o uso do conceito modo de conceitualização para descrever o oportunismo e a contingência da conceitualização. A abordagem das competências de longo prazo é alvo da teoria dos campos conceituais (VERGNAUD, 2013), porém muitas vezes não temos esquemas prévios e precisamos construí-los, portanto, enxergar a conceitualização como um processo de gradação contínua entre o oportunismo e a sistemática (FANARO; OTERO; MOREIRA, 2009) nos permitiu abordar a questão a partir da noção de modo de conceitualização.

A abordagem da aprendizagem na etapa operatória do conhecimento/abordagem das UEPS é outro ponto que destacamos neste artigo como implicação para a pesquisa em Ensino de Física/Ciências, pois muitas UEPS ocupam-se de analisar processos de aprendizagem significativa na perspectiva predicativa ao usar a teoria ausubeliana como referencial teórico para avaliação da aprendizagem. Ausubel restringe a análise ao conhecimento predicativo (VERGNAUD, 2013), enquanto a teoria dos campos conceituais permite a análise da cognição tanto na forma predicativa como na forma operatória do conhecimento. Dessa forma, Vergnaud oferece uma modalidade de análise mais completa da aprendizagem, ainda pouco explorada nas pesquisas em Ensino de Ciências.

\section{Agradecimentos}

$\mathrm{O}$ primeiro autor desse trabalho agradece à professora Eliane Angela Veit por encorajá-lo, em comunicação pessoal, a escrevê-lo. Ele também é grato a todo apoio emocional e afetivo de sua companheira, Amanda Cantal, sobretudo durante a pandemia da COVID-19 (que ainda não acabou). Os dois autores agradecem aos pareceristas e à editora pelos valiosos apontamentos feitos para melhora da qualidade do trabalho.

\section{Referências bibliográficas}

ARAUJO, I. S.; VEIT, E. A.; MOREIRA, M. A. Simulações computacionais na aprendizagem da Lei de Gauss para a eletricidade e da Lei de Ampère em nível de Física Geral. Revista Electrónica de Enseñanza de las Ciencias, Vigo, v. 6, n. 3, p. 601-629, setdez. 2007.

BACHELARD, G. A formação do espírito científico. Rio de Janeiro: Contraponto, 1996. $314 \mathrm{f}$. 
BARDIN, L. Análise de Conteúdo. Lisboa: Edições 70, 2008. 281 p.

BUNGE, M. Caçando a realidade: a luta pelo realismo. São Paulo: Perspectiva, 2010. 458 p.

EYSENCK, M.; KEANE, M. Psicologia Cognitiva. Porto Alegre: Artes Médicas, 1994. 490 p.

FANARO, M. A.; OTERO, M. R.; MOREIRA, M. A. Teoremas-en-acto y conceptos-en-acto em dos situaciones relativas a la noción de sistema cuántico. Revista Brasileira de Pesquisa em Educação em Ciências, Belo Horizonte, v. 9, n. 3, set-dez. 2009.

FURIÓ, C.; GUISASOLA, J.; ZUBIMENDI, J. Problemas históricos y dificultades de aprendizaje en la interpretación newtoniana de fenómenos electrostáticos considerados elementales. Investigações em Ensino de Ciências, v. 3, n.3, p. 165-188, set-dez. 1998.

GUISASOLA, J.; ALMUDÍ, J.; FURIÓ, C. The nature of Science and Its implications for Physics textbooks. Science \& Education, New York, v. 14, n. 3-5, p. 321-338, jul. 2005.

GUISASOLA, J.; ALMUDÍ, J.; SALINAS, J.; ZUZA, K.; CERBERIO, M. Dificultades persistentes en el aprendizaje de la electricidad: estrategias de razonamiento de los estudiantes al explicar fenómenos de carga eléctrica. Enseñanza de las Ciencias, Barcelona, v. 26, n. 2, p. 177-192, set-dez. 2008.

GUISASOLA, J.; ZUZA, K.; ALMUDÍ, J. An analysis of how electromagnetic induction and Faraday's law are presented in general physics textbooks, focusing on learning difficulties. European Journal of Physics, Bristol, v. 34, n. 4, p. 1015-1024, jul-ago. 2013.

JELICIC, K.; PLANINIC, M.; PLASINIC, G. Analyzing high school students' reasoning about electromagnetic induction. Physical Review Physics Education Research, Maryland, v. 13, n. 1, p. 010112, jan-dez. 2017.

KALKANIS, G.; HADZIDAKI, P.; STAVROU, D. An instructional model for a radical conceptual change towards quantum mechanics concepts. Science Education, Dordrecht, v. 87, n. 2, mar. 2003.

KUO, E.; WIEMAN, C. Towards instructional design principles: inducing Faraday's law with contrasting cases. Physical Review Physics Education Research, v. 12, n. 1, p.1-14, jan-dez. 2016. 
MARKMAN, A. Knowledge Representation. Londres: Psychology Press. 1999. 344 p.

MARTIN, J.; SOLBES, J. Diseño y evaluación de uma propuesta para la enseñanza del concepto de campo en Física. Enseñanza de las Ciencias, v. 19, n. 3, p. 393-403, set-dez. 2001 .

MOREIRA, M. A. Unidades de enseñanza potencialmente significativas. Aprendizagem Significativa em revista, Porto Alegre, v. 1, n. 1, p. 43-64, jan-abr. 2011.

MORTIMER, E. Construtivismo, mudança conceitual e Ensino de Ciências: para onde vamos? Investigações em Ensino de Ciências, Porto Alegre, v. 1, n. 1, p. 20-39, abr. 1996.

NOUSIANEN, M.; KOPONEN, I. Pre-service teachers' content knowledge of electric and magnetic field concepts: conceptual facets and their balance. European Journal of Science and Mathematics Education, Famagusta, v. 5, n. 1, p. 74-90, jan-abr. 2017.

NUSSENZVEIG, H. M. Um curso de Física Básica. São Paulo: Edgard Blucher. 2006. 323 p. v. 3 .

PANTOJA, G. C.; MOREIRA, M. A. Investigando a implementação de uma Unidade de Ensino Potencialmente Significativa sobre o conceito de Campo Magnético em disciplinas de Física Geral. Revista Electrónica de Investigación en Educación en Ciencias, Buenos Aires, v. 14, n. 2, p. 1-16, dez. 2019.

PANTOJA, G. C.; MOREIRA, M. A. Conceitualização do conceito de campo elétrico de estudantes de Ensino Superior em Unidades de Ensino Potencialmente Significativas sobre eletrostática. Revista Brasileira de Ensino de Física, São Paulo, v. 42, e20200288, 2020.

PANTOJA, G. C. Campos Conceituais e Indução Eletromagnética: Classificação de Problemas em Eletrodinâmica. Revista Brasileira de Pesquisa em Educação em Ciências, Belo Horizonte, v. 21, p. 1-33, mai. 2021.

THONG, W.; GUNSTONE, R. Some Student Conceptions of Electromagnetic Induction. Research in Science Education, New York, v. 38, n. 1, p. 31-44, jan. 2008.

VERGNAUD, G. The theory of conceptual fields. Human development, Basiléia, v. 52, n. 2, p. 83-94, abr. 2009. 
VERGNAUD, G. Conceptual Development and learning. Revista Qurriculum, La Laguna, v. 26, p. 39-59, mar. 2013.

VIENNOT, L.; RAINSON, S. Design and evaluation of reseach-based teaching sequence: the superposition of electric field. International Journal of Science Education, Abingdon, v. 19, n. 1, p. 1-16, jan. 1999.

ZUZA, K.; ALMUDÍ, J.; LENIZ, A.; GUISASOLA, J. Adressing students' difficulties with Faraday's law: a guided problem-solving approach. Physical Review Special Topics Physics Education Research, Maryland, v. 10, n.1, p. 1-16, jan-dez. 2014.

ZUZA, K.; GARCÍA, J. M.; GUISASOLA, J. Revisión de la investigación acerca de las ideas de los estudiantes sobre la interpretación de los fenómenos de inducción electromagnética. Enseñanza de las ciencias, Barcelona, v. 30, n. 2, p. 175-196, mai-ago. 2012.

WHITTAKER, E. A history of the theories of aether and electricity: from the age of Descartes to the close of the nineteenth century (1910). Whitefish: Kessinger Publishing, 1910. $475 \mathrm{f}$. 